Open Access

\title{
Secretome profiling of Cryptococcus neoformans reveals regulation of a subset of virulence-associated proteins and potential biomarkers by protein kinase $A$
}

\author{
Jennifer M. H. Geddes ${ }^{1,2}$, Daniel Croll ${ }^{1}$, Mélissa Caza ${ }^{1}$, Nikolay Stoynov ${ }^{3}$, Leonard J. Foster ${ }^{3}$
} and James W. Kronstad ${ }^{1,2^{*}}$

\begin{abstract}
Background: The pathogenic yeast Cryptococcus neoformans causes life-threatening meningoencephalitis in individuals suffering from HIV/AIDS. The cyclic-AMP/protein kinase A (PKA) signal transduction pathway regulates the production of extracellular virulence factors in C. neoformans, but the influence of the pathway on the secretome has not been investigated. In this study, we performed quantitative proteomics using galactose-inducible and glucose-repressible expression of the PKA1 gene encoding the catalytic subunit of PKA to identify regulated proteins in the secretome.

Methods: The proteins in the supernatants of cultures of $C$. neoformans were precipitated and identified using liquid chromatography-coupled tandem mass spectrometry. We also employed multiple reaction monitoring in a targeted approach to identify fungal proteins in samples from macrophages after phagocytosis of C. neoformans cells, as well as from the blood and bronchoalveolar fluid of infected mice.

Results: We identified 61 secreted proteins and found that changes in PKA1 expression influenced the extracellular abundance of five proteins, including the Cig1 and Aph1 proteins with known roles in virulence. We also observed a change in the secretome profile upon induction of Pka1 from proteins primarily involved in catabolic and metabolic processes to an expanded set that included proteins for translational regulation and the response to stress. We further characterized the secretome data using enrichment analysis and by predicting conventional versus non-conventional secretion. Targeted proteomics of the Pka1-regulated proteins allowed us to identify the secreted proteins in lysates of phagocytic cells containing C. neoformans, and in samples from infected mice. This analysis also revealed that modulation of PKA1 expression influences the intracellular survival of cryptococcal cells upon phagocytosis.

Conclusions: Overall, we found that the CAMP/PKA pathway regulates specific components of the secretome including proteins that affect the virulence of $C$. neoformans. The detection of secreted cryptococcal proteins from infected phagocytic cells and tissue samples suggests their potential utility as biomarkers of infection. The proteomics data are available via ProteomeXchange with identifiers PXD002731 and PASS00736.
\end{abstract}

Keywords: Quantitative proteomics, Fungal pathogenesis, Secretome, PKA, Virulence factors, Biomarkers, Multiple reaction monitoring

\footnotetext{
* Correspondence: kronstad@msl.ubc.ca

${ }^{1}$ Michael Smith Laboratories, University of British Columbia, Vancouver, BC

V6T 1Z4, Canada

${ }^{2}$ Department of Microbiology and Immunology, University of British

Columbia, Vancouver, BC V6T 1Z4, Canada

Full list of author information is available at the end of the article
}

\section{Biomed Central}

(c) 2015 Geddes et al. Open Access This article is distributed under the terms of the Creative Commons Attribution 4.0 International License (http://creativecommons.org/licenses/by/4.0/), which permits unrestricted use, distribution, and reproduction in any medium, provided you give appropriate credit to the original author(s) and the source, provide a link to the Creative Commons license, and indicate if changes were made. The Creative Commons Public Domain Dedication waiver (http://creativecommons.org/publicdomain/zero/1.0/) applies to the data made available in this article, unless otherwise stated. 


\section{Background}

Cryptococcus neoformans is an opportunistic, yeast-like fungus that is a significant threat to immunocompromised individuals such as patients with HIV/AIDS $[1,2]$. The ability of $C$. neoformans to cause disease depends on the production of virulence factors including a polysaccharide capsule, melanin deposition in the cell wall, the ability to grow at $37^{\circ} \mathrm{C}$, and the secretion of extracellular enzymes [3-8]. Extracellular enzymes with roles in virulence include phospholipases, which hydrolyze ester bonds and aid in the degradation and destabilization of host cell membranes and cell lysis, and urease, which hydrolyzes urea to ammonia and carbamate, inducing a localized increase in $\mathrm{pH}$ [9-12]. Proteinases may also cause tissue damage, provide nutrients to the pathogen and facilitate migration to the central nervous system [13-15]. In general, the secretion of extracellular enzymes is important for fungal survival within the host but a comprehensive investigation of the secretome and its regulation by the cyclic-AMP/Protein Kinase A (PKA) signal transduction pathway has not been performed for C. neoformans.

The cAMP/PKA pathway regulates capsule production, melanin formation, mating, and virulence in $C$. neoformans [16-20]. Components of the pathway include a $\mathrm{G} \alpha$ protein (Gpa1), adenylyl cyclase (Cac1), adenylyl cyclase-associated protein (Aca1), a candidate receptor (Gpr4), phosphodiesterases (Pde1 and Pde2), and the PKA catalytic (Pka1, Pka2) and regulatory (Pkr1) subunits. In response to environmental signals, including exogenous methionine and nutrient starvation, the Gprotein coupled receptor (GPCR), Gpr4 undergoes a conformational change to activate $\mathrm{Cacl}$ and subsequently stimulate the production of cAMP. Mutations in genes encoding the Gpa1, Cac1, Aca1, and Pka1 proteins result in reduced formation of capsule and melanin, as well as sterility and attenuated virulence in a mouse model of cryptococcosis $[16,21]$. In particular, Pka1 is a key regulator of virulence in C. neoformans. In contrast, disruption of the gene encoding Pkr1 results in enlargement of the capsule and hypervirulence [17].

Previous transcriptional profiling experiments compared a wild-type strain with $p k a 1 \Delta$ and $p k r 1 \Delta$ mutants of C. neoformans, and identified differences in transcript levels for genes related to cell wall synthesis, transport (e.g., iron uptake), the tricarboxylic acid cycle, and glycolysis [22]. Differential expression patterns were also observed for genes encoding ribosomal proteins, stress and chaperone functions, secretory pathway components and phospholipid biosynthetic enzymes. Specifically, loss of PKA1 influenced the expression of genes involved in secretion, and Pka1 was hypothesized to influence capsule formation by regulating expression of secretory pathway components that control the export of capsular polysaccharide to the cell surface. Additionally, the secretion inhibitors brefeldin A, nocodazole, monensin, and NEM reduced capsule size, a phenotype similar to that observed in a pka1 mutant [22]. In general, the mechanisms and components required for the export of capsule polysaccharide and other virulence factors in $C$. neoformans are poorly understood. Beyond the role of PKA, other studies have examined exocytosis functions (Sec6, Sec14), the secretion of phospholipases, and the involvement of extracellular vesicles [23-28]. Additionally, O'Meara et al. (2010) recently demonstrated that PKA influences capsule attachment via phosphorylation of the pH-responsive transcription factor Rim101, a key regulator of cell wall functions.

The role of PKA in secretion in C. neoformans has also been examined with strains carrying galactose-inducible and glucose-repressible versions of PKA1 and PKR1 constructed by inserting the GAL7 promoter upstream of the genes [29]. Elevated Pka1 activity, stimulated by growth of the $P_{G A L 7:: P K A 1 \text { strain in galactose-containing }}$ media, was found to influence capsule thickness, cell size, ploidy, and vacuole enlargement [29]. The authors also showed that Pka1 activity was required for wildtype levels of melanization and laccase activity, and influenced the correct localization of laccase. The ability to regulate expression of $P K A 1$ and, subsequently, the activity of Pka1, is a powerful tool for investigating the mechanisms of its influence on the secretion of virulence factors and secretory pathway components.

In this study, we used the strain with galactoseinducible and glucose-repressible expression of PKA1 to investigate the influence of Pka1 on the secretome using quantitative proteomics. We identified 61 different secreted proteins and found that Pka1 regulated the extracellular abundance of five. These proteins included three enzymes ( $\alpha$-amylase, acid phosphatase, and glyoxal oxidase), the Cig1 protein (cytokine-inducing glycoprotein) associated with virulence and heme uptake, and a novel protein containing a carbohydrate-binding domain (CNAG_05312). We also observed a change in the secretome profile under $\mathrm{Pka} 1$-inducing conditions from proteins involved primarily in catabolic and metabolic processes to an expanded set that included proteins for translational regulation and the response to stress. Enrichment analysis of our Pka1-influenced secretome data compared to the whole genome showed over-representation of genes associated with a broad spectrum of processes including metabolic and catabolic processing. Although no enrichment was observed between our secretome data and the Fungal Secretome KnowledgeBase (FunSecKB), a comparison of GO terms between the data sets showed the majority of our identified proteins to be represented in the FunSecKB. Next, we exploited our secretome data using a targeted proteomics approach to identify potential biomarkers of cryptococcal infection. Multiple Reaction Monitoring 
(MRM) in the presence of stable isotope dilutions (SID) allows for identification and quantification of specific peptides in a sample. Specifically, we were able to identify Pka1-regulated proteins of $C$. neoformans in host samples including blood, bronchoalveolar lavage fluid, and infected macrophage lysates. Overall, our study reveals that the cAMP/PKA pathway regulates specific components of the secretome including the Cig1 and Aph1 proteins that contribute to virulence in C. neoformans.

\section{Results}

\section{Control of PKA1 expression results in a change of the protein secretion profile}

Given the virulence defect of a $p k a 1$ mutant, we hypothesized that Pka1 influences the secretion of proteins associated with the virulence and survival of $C$. neoformans in the host. To test this idea, we quantitatively identified proteins secreted by $C$. neoformans in the context of regulated expression of PKA1. For our initial analysis, we collected supernatant cultures of WT and $P_{G A L 7:: P K A 1}$ strains grown under Pka1-repressed (glucose) and Pka1-induced (galactose) conditions at 16, 48,72 , and $120 \mathrm{~h}$ post-inoculation (hpi), and analyzed the samples using quantitative mass spectrometry. The analysis of these supernatant samples resulted in the identification of 164 (54 quantifiable) and 207 (83 quantifiable) proteins under Pka1-repressed and Pka1induced conditions, respectively (see Additional file 1: Table S1; Additional file 2: Table S2). As shown in Table 1, 23 proteins were identified and quantified under Pka1-repressed and Pka1-induced conditions at the specified time-points. We found that none of the changes in protein abundance between the two conditions were statistically significant $(p>0.05)$ and therefore, concluded that Pka1 did not influence the abundance of any of the observed proteins under the conditions tested. However, upon comparison of the unique proteins identified under either Pka1-repressed or Pka1-induced conditions, using Gene Ontology (GO) term biological classifications at all time points, we were able to observe overall changes in the secretome profiles under the influence of Pka1 (Fig. 1). Additional differentially expressed proteins may be present in the samples, but we were unable to measure their abundance and they were therefore not included for further analysis. Under Pka1-repressed conditions, the majority of secreted proteins were associated with catabolic and metabolic (33\%), unknown (20 \%), and hypothetical (20 \%) processes (totaling $73 \%)$, with additional proteins associated with transport (8\%), oxidation-reduction processes $(4 \%)$, dephosphorylation (4\%), proteolysis (4\%), glycolysis (4\%), and regulation of transcription (3\%). Conversely, a change in the secretome profile was observed under the Pka1-induction condition. Here, we again observed the majority of proteins to be associated with catabolic and metabolic (26\%), unknown (19\%), and hypothetical (17\%) processes (totaling $62 \%$ ). A slight decline was found for proteins associated with transport (from 8 to $6 \%$ ), oxidationreduction processes (from 4 to $3 \%$ ), dephosphorylation (from 4 to $2 \%$ ), proteolysis (from 4 to $3 \%$ ), and regulation of transcription (from 3 to $0 \%$ ). However, a greater emphasis was found for proteins associated with glycolysis (from 4 to $6 \%$ ), response to stress (from 0 to $8 \%$ ), translation (from 0 to $7 \%$ ), and nucleosome assembly (from 0 to $3 \%$ ). Although, our secretome analysis at specific times did not identify Pka1-regulated proteins, a change toward the secretion of proteins for glycolysis, translational regulation, nucleosome assembly, and the response to stress was observed upon induction of PKA1 expression.

\section{Identification of secreted proteins regulated by Pka1}

Given that we identified secreted proteins from strains with modulated Pka1 activity, but did not observe any proteins whose abundance was directly regulated by Pka1, we extended our analysis to examine protein secretion at an intermediate time point of $96 \mathrm{hpi}$, and we used an alternative, less stringent method for protein precipitation (EtOH/acetate). We chose an end-point collection time of 96 hpi based on our coverage of a range of other time points in the previous analysis and because this time was sufficient for the culture to reach stationary phase and to accumulate proteins in the extracellular environment. Additionally, because we did not observe changes in protein abundance under regulation of Pka1 following the time-point analysis, we used the alternative protein precipitation method in an attempt to obtain a more comprehensive view of the secretome. We collected supernatant cultures of WT and $P_{G A L 7}:: P K A 1$ strains grown under Pka1-repressed (glucose) and Pka1-induced (galactose) conditions at 96 hpi and analyzed the samples using quantitative mass spectrometry. Similar trends in protein abundance were observed for the majority of proteins in both experimental approaches (EtOH and TCA/acetone precipitation) (see Additional file 3: Table S3) [30]. Although the variability of the time-point analysis was relatively high, the reproducibility observed from the end-point analysis suggested that collecting the samples at different timepoints impacted the protein abundance and contributed to the observed variability. This impact may be associated with culture sampling, as well as changes in capsule production during the early- to mid-log growth phases of the fungal cultures [29]. We identified 61 proteins under Pka1-repressed conditions of which 34 were successfully dimethyl-labeled and quantified (Table 2; see Additional file 4: Table S4). These 34 proteins covered a broad spectrum of biological classifications (17 categories) for GO terms, including proteins associated with 
Table 1 Proteins identified in the secretome of C. neoformans collected at 16, 48, 72, and 120 hpi grown in Pka1-repressed (glucose-containing medium) and Pka1-induced (galactose-containing medium) conditions

\begin{tabular}{|c|c|c|c|c|c|c|c|}
\hline \multirow{2}{*}{$\begin{array}{l}\mathrm{GO} \\
\text { categories }^{\mathrm{a}}\end{array}$} & \multirow{2}{*}{$\begin{array}{l}\text { Accession } \\
\text { number }\end{array}$} & \multirow[t]{2}{*}{ Protein Name } & \multirow[b]{2}{*}{ Time point } & \multicolumn{2}{|l|}{ Fold change $\mathrm{b}^{\mathrm{b}^{*}}$} & \multicolumn{2}{|l|}{ Std. Dev. } \\
\hline & & & & Pka1-repression & Pka1-induction & Pka1-repression & Pka1-induction \\
\hline \multicolumn{8}{|c|}{ Carbohydrate catabolic process } \\
\hline & CNAG_02189 & a-Amylase & 16 hpi & 0.298 & 1.096 & 0.314 & 1.270 \\
\hline \multicolumn{8}{|c|}{ GTP catabolic process } \\
\hline & CNAG_06125 & Translation elongation factor 1 a & 16 hpi & 0.135 & 0.379 & 0.145 & 0.517 \\
\hline \multicolumn{8}{|c|}{ Carbohydrate metabolic process } \\
\hline & CNAG_01239 & Chitin deacetylase & 16 hpi & 0.906 & 1.350 & 0.310 & 0.515 \\
\hline & CNAG_04245 & Chitinase & 16 hpi & 0.448 & 0.286 & 0.007 & 0.296 \\
\hline & & & 48 hpi & 0.826 & 0.603 & 1.019 & 0.017 \\
\hline & CNAG_06501 & 1,3- $\beta$-glucanosyltransferase & 16 hpi & 0.573 & 0.896 & 0.383 & 0.169 \\
\hline \multicolumn{8}{|c|}{ Transmembrane transport } \\
\hline & CNAG_02974 & $\begin{array}{l}\text { Voltage-dependent ion-selective } \\
\text { channel }\end{array}$ & 16 hpi & 0.223 & 0.466 & 0.089 & 0.645 \\
\hline \multicolumn{8}{|c|}{ Oxidation-reduction process } \\
\hline & CNAG_03465 & Laccase & 16 hpi & 0.637 & 0.870 & 0.651 & 1.038 \\
\hline \multicolumn{8}{|c|}{ Unknown/Unclassified } \\
\hline & CNAG_02030 & Glyoxal oxidase & 16 hpi & 0.278 & 0.600 & 0.324 & 0.672 \\
\hline & & & 48 hpi & 0.242 & 0.350 & 0.063 & 0.144 \\
\hline & CNAG_06267 & Rds1 protein & 16 hpi & 0.336 & 0.756 & 0.303 & 0.222 \\
\hline & & & 120 hpi & 0.860 & 5.106 & 0.444 & 4.588 \\
\hline & CNAG_00776 & Immunoreactive mannoprotein MP88 & 16 hpi & 0.627 & 0.994 & 0.214 & 1.193 \\
\hline & CNAG_02864 & Predicted protein & 16 hpi & 0.346 & 0.259 & 0.056 & 0.183 \\
\hline & CNAG_04753 & Lactonohydrolase & 16 hpi & 1.031 & 0.751 & 0.631 & 0.413 \\
\hline & & & 48 hpi & 1.250 & 1.055 & 0.996 & 0.546 \\
\hline \multicolumn{8}{|l|}{ Hypothetical } \\
\hline & CNAG_00587 & Hypothetical protein & 16 hpi & 1.275 & 1.620 & 0.018 & 0.371 \\
\hline & CNAG_01047 & Hypothetical protein & 16 hpi & 0.279 & 0.471 & 0.070 & 0.272 \\
\hline & & & 72 hpi & 0.928 & 0.719 & 1.034 & 0.432 \\
\hline & CNAG_03492 & Hypothetical protein & 16 hpi & 0.506 & 0.799 & 0.400 & 0.030 \\
\hline & & & 72 hpi & 0.640 & 1.180 & 0.199 & 0.431 \\
\hline & CNAG_05893 & Hypothetical protein & 48 hpi & 1.609 & 1.676 & 1.380 & 1.639 \\
\hline & & & 120 hpi & 1.641 & 1.413 & 0.953 & 0.348 \\
\hline
\end{tabular}

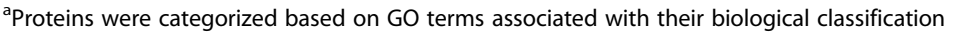

${ }^{b}$ Fold change is reported as the average quantification for $P_{G A L} \because: P K A 1 \mathrm{vs}$. WT, \pm standard deviation

* Statistical analysis was performed using a Student's $t$-test between the conditions. None of the comparisons resulted in a significant difference in protein

abundance ( $p$-value $>0.05)$

catabolic and metabolic processes, ubiquitination, transport, dephosphorylation, glycolysis, oxidation-reduction, translation, proteolysis, and the response to stress. Under Pka1-induced conditions, we identified 38 proteins, of which 21 were successfully dimethyl-labeled and quantified (Table 3; see Additional file 5: Table S5). These 21 proteins covered 11 biological classifications for GO terms and included proteins associated with catabolic and metabolic processes, along with ubiquitination, transport, dephosphorylation, oxidation-reduction, proteolysis, and the response to stress. In total, 17 proteins were present under both Pka1-repressed and Pka1-induced conditions. A comparison of changes in abundance under Pka1-repressed and Pka1-induced conditions of these 17 proteins revealed that five showed statistically significant differences ( $p$-value $<0.05$, Student's $t$-test $)$ in abundance in response to regulation of Pka1 (Fig. 2). We concluded that the extracellular abundance of these five proteins was influenced by PKA and we focused our subsequent analysis on these proteins. Under 


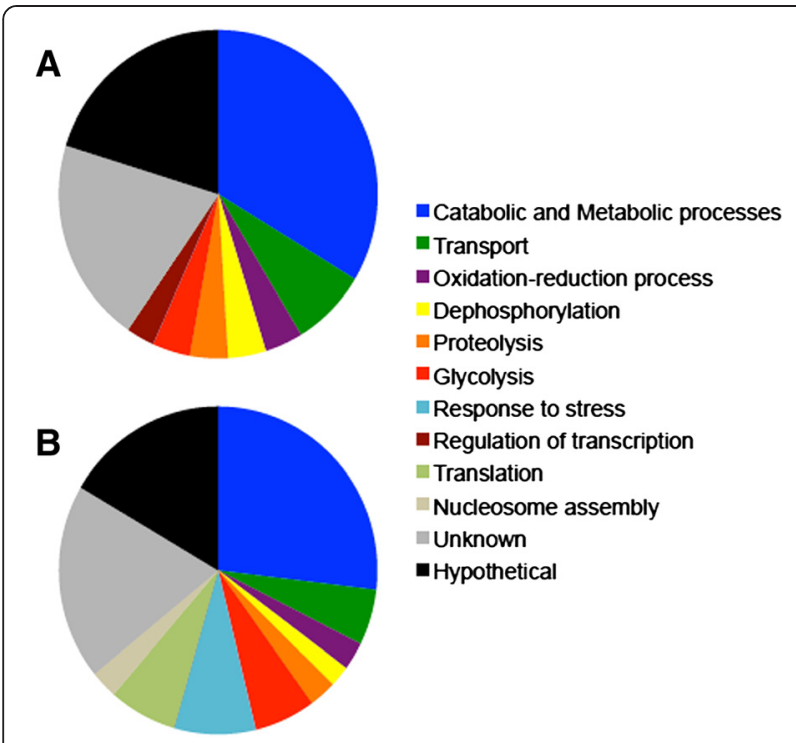

Fig. 1 Quantitative proteomic analysis of the C. neoformans secretome over the course of all time-points (16, 48, 72, and 120 hpi) under (a) Pka1-repressed (glucose) and (b) Pka1-induced (galactose) conditions. Identified proteins were grouped according to GO terms associated with their biological classifications. GO term classification was performed on unique proteins identified under either Pka1-repressed or Pka1-induced conditions to highlight the overall influence of Pka1 regulation on the secretome profile

Pka1-induced conditions, a cytokine-inducing glycoprotein (Cig1), an $\alpha$-amylase, a glyoxal oxidase, and a novel protein (CNAG_05312) each showed an increase in abundance, whereas an acid phosphatase (Aph1) showed a decrease in abundance. Taken together, these findings suggest that Pka1 regulates the extracellular abundance of specific proteins secreted by $C$. neoformans.

\section{Gene ontology analyses of the secretome revealed enrichment of proteins associated with metabolic and catabolic processes}

Based on our identification and quantification of 192 proteins in the secretome of $C$. neoformans, we next sought to classify the corresponding genes according to their GO terms of biological process, cellular component, and molecular function. Our goal was to assess whether subsets of genes showed significant over-representation relative to all genes in C. neoformans. To perform the enrichment analysis, all unique proteins identified under Pka1repressed conditions were combined into a single data set as were proteins identified under Pkal-induced conditions. As shown in Fig. 3, the identified secreted proteins under Pka1-repressed conditions were enriched in 15 biological categories, with the most significant enrichment associated with carbohydrate metabolic process, catabolic process, generation of precursor metabolites and energy, organic substance metabolic process, and primary metabolic process. Under Pka1-induced conditions, enrichment was only associated with the five most significantly enriched categories under Pka1-repressed conditions. Classification by cellular components showed the most significant enrichment associated with the cytoplasm under both conditions, which may be an artifact of the classification process or indicative of the location of protein synthesis (see Additional file 6: Figure S1), whereas classification by molecular function showed no enrichment.

Our gene sets were also compared to all reported secreted proteins in the Fungal Secretome Knowledge Base (FunSecKB) for C. neoformans strain JEC21 [31, 32]. The analysis showed no significant enrichment; however, similarities among the identified GO terms were observed (Fig. 4). Forty-seven GO term categories were shared between the FunSecKB and our identified proteins under Pka1-repressed and Pka1-induced conditions; the greatest number of proteins being associated with metabolic processes. Twenty-five categories were represented only in our secretome data, and one category (GO:0009607; response to biotic stimulus) was represented only in the FunSecKB. Upon comparison of GO term categories for cellular components, 16 categories were shared between the FunSecKB and our identified proteins under Pka1-repressed and Pka1-induced conditions; the greatest number of proteins being associated with the cell, cytoplasm, and intracellular categories (see Additional file 7: Figure S2). Upon comparison of GO term categories for molecular function, 17 categories were shared between the FunSecKB and our identified proteins under Pka1-repressed and Pka1-induced conditions; the greatest number of proteins associated with binding as well as enzyme activity (see Additional file 8: Figure S3). Taken together, the enrichment analysis of our secretome data under modulation of Pka1 activity compared to the whole genome showed over-representation of genes associated with a broad spectrum of processes including metabolic and catabolic processing. Although no enrichment was observed between our secretome data and the FunSecKB, a comparison of GO terms between the data sets showed all but one of our identified proteins to be represented in the FunSecKB.

\section{A bioinformatic analysis of the secretome predicts modes of secretion}

We next examined the secreted proteins, under modulation of Pkal activity, for the presence of predicted signal peptides and GPI anchors. Specifically, we used SignalP 4.1, Signal-3 L, and Phobius for the prediction of protein extracellular location based on the presence or absence of $\mathrm{N}$-terminal signal peptides. The presence of a signal peptide suggests conventional secretion versus potential non-conventional export if a signal peptide is absent. Additionally, we 
Table 2 Proteins identified in the secretome of C. neoformans collected at 96 hpi from cells grown in Pka1-repressed (glucose-containing medium) conditions

$\mathrm{GO}_{\text {categories }}{ }^{\mathrm{a}} \quad$ Accession number

$$
\text { Protein name }
$$

a-Amylase

Translation elongation factor 1 a

$$
\text { Endo-1,3(4)- } \beta \text {-glucanase }
$$

1,3- $\beta$-glucanosyltransferase

Chitin deacetylase

Deacetylase

Chitin deacetylase

Malate dehydrogenase

Phosphogluconate dehydrogenase

Polyubiquitin

FOF1 ATP synthase subunit $\beta$

ATPase a subunit

Eukaryotic ADP/ATP carrier

5-methyltetrahydropteroyltriglutamatehomocysteine S-methyltransferase

Acid phosphatase

1.862

Phosphopyruvate hydratase

3.093

$\mathrm{Cu} / \mathrm{Zn}$ superoxide dismutase

Laccase

0.302

0.718

Carboxypeptidase D

4.664

1.883

$\mathrm{Hsc} 70-4$

Ribosomal protein L13

Cytokine-inducing glycoprotein

0.134

0.719

0.583

0.513

3.409

Std. Dev.

0.019

2.181

0.583

0.100

0.775

0.778

0.584

0.546

$>10$

0.396

0.249

0.387

9.753

0.327

0.083

3.377

0.161

0.668

2.094

0.057

Glycosyl-hydrolase

0.230

0.287

Glyoxal oxidase

0.109

Rds1 protein

0.106 
Table 2 Proteins identified in the secretome of C. neoformans collected at 96 hpi from cells grown in Pka1-repressed (glucose-containing medium) conditions (Continued)

\begin{tabular}{|c|c|c|c|c|}
\hline \multicolumn{5}{|l|}{ Hypothetical } \\
\hline & CNAG_05312 & Conserved hypothetical protein & 0.341 & 0.100 \\
\hline & CNAG_03007 & Conserved hypothetical protein & 0.518 & 0.649 \\
\hline & CNAG_01562 & Conserved hypothetical protein & 0.942 & 0.194 \\
\hline & CNAG_05893 & Conserved hypothetical protein & 0.991 & 0.487 \\
\hline & CNAG_01047 & Conserved hypothetical protein & 6.714 & 6.494 \\
\hline & CNAG_00588 & Conserved hypothetical protein & $>10$ & $>10$ \\
\hline & CNAG_03223 & Conserved hypothetical protein & $>10$ & $>10$ \\
\hline & CNAG_00586 & Conserved hypothetical protein & $>10$ & $>10$ \\
\hline
\end{tabular}

${ }^{\text {a }}$ Proteins were categorized based on GO terms associated with their biological classification

${ }^{\mathrm{b}}$ Fold change is reported as the average quantification for $P_{G A L}:: P K A 1$ vs. WT, \pm standard deviation

used GPI-SOM to predict the presence or absence of a GPI-anchor on proteins, indicative of plasma membrane association, which may or may not be capable of dissociation and subsequent protein secretion. Of the 61 proteins used for this analysis, 14 had both an $\mathrm{N}$-terminal signal peptide and a GPI-anchor protein, 17 had only an N-terminal signal peptide, one had a GPI-anchor but no N-terminal signal peptide, and 29 proteins did not have an $\mathrm{N}$-terminal signal peptide or a GPI-anchor (Table 4). Taken together, these results suggest that $C$. neoformans may employ a nonconventional secretory pathway for regulation of part of its secretome, including potential protein secretion via vesicle export [24].

\section{Examination of transcription and protein abundance in the context of $\mathrm{Pka1}$ regulation}

Based on our identification and quantification of five secreted proteins regulated by Pka1 in C. neoformans, we evaluated whether transcript levels were also influenced by Pka1 regulation and whether there was a correlation with the observed regulation of protein abundance. Specifically, we performed qRT-PCR on RNA collected at 16 and 96 hpi from cells grown in Pka1-repressed and Pka1-induced conditions for the WT and $P_{G A L 7:: P K A 1}$ strains, and compared the observed values to our quantitative proteomic results at 96 hpi. Figure 5 summarizes the RNA expression levels at 16 hpi and 96 hpi and protein abundance at 96 hpi for Cig1, the acid phosphatase Aph1, an $\alpha$-amylase, a glyoxal oxidase, and a novel protein (CNAG_05312). Cig1 and the novel protein both showed down-regulation of their transcripts under Pka1repressed conditions at 16 and $96 \mathrm{hpi}$, followed by minimal or slight up-regulation with induced Pka1 activity. $\alpha$-Amylase and glyoxal oxidase showed an initial peak in transcript levels at $16 \mathrm{hpi}$, followed by minimal change or a decrease in RNA levels at 96 hpi under Pka1repressed conditions, and the transcript levels decreased in response to Pka1 induction. Acid phosphatase showed elevated transcript levels upon PKA1 repression at both time points, compared to a drop in RNA levels at $16 \mathrm{hpi}$ or no change at 96 hpi upon induction of PKA1. In general, Pkal appears to positively regulate the transcript levels of Cig1 and the novel protein (CNAG_05312), and to negatively regulate the transcript levels of the other three proteins. Taken together, our results suggest that although Pka1 activity influences the transcript levels and extracellular abundance of the five proteins, a correlation between transcript and protein levels was not always observed, and this was particularly notable for glyoxal oxidase. The differences may indicate additional levels of potential influence of Pka1 beyond transcriptional regulation, including differences in mRNA versus protein stability, the timing of expression and the regulation of protein export. For example, more detailed studies will be needed to examine the timing of intracellular and extracellular accumulation of the glyoxal oxidase protein relative to transcription of the gene.

\section{Detection of secreted Pka1-regulated proteins using Multiple Reaction Monitoring}

Based on our identification of five Pka1-regulated proteins, including two with roles in virulence, we hypothesized that these proteins would be secreted during infection and that they might be potentially useful biomarkers of cryptococcosis. To test this idea, we used Multiple Reaction Monitoring (MRM), a powerful and targeted proteomics approach for the relative quantitative measurement of target proteins. In the presence of an internal standard, a stable isotope-labeled peptide, the amount of natural protein can be measured by comparing the signals to the labeled species. The isotopically labeled, proteotypic peptides terminate with C-terminal heavy arginine or lysine (C-term $\operatorname{Arg} \mathrm{U}_{-}{ }^{13} \mathrm{C}_{6} ; \mathrm{U}_{-}{ }^{15} \mathrm{~N}_{4}$ or Lys $\mathrm{U}_{-}{ }^{13} \mathrm{C}_{6} ; \mathrm{U}_{-}{ }^{15} \mathrm{~N}_{2}$ ). In principle, the stable isotopes have the same physiochemical properties as the natural peptides and only differ by mass resulting in co-elution of the peptides. However, studies have suggested that in the 
Table 3 Proteins identified in the secretome of C. neoformans collected at 96 hpi from cells grown in Pka1-induced (galactose-containing medium) conditions

\begin{tabular}{|c|c|c|c|c|}
\hline 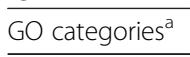 & Accession number & Protein name & Fold change $^{b}$ & Std. Dev. \\
\hline \multicolumn{5}{|c|}{ Carbohydrate catabolic process } \\
\hline & CNAG_02189 & a-Amylase & 1.061 & 0.080 \\
\hline \multicolumn{5}{|c|}{ GTP catabolic process } \\
\hline & CNAG_06125 & Translation elongation factor 1 a & 0.462 & 0.555 \\
\hline \multicolumn{5}{|c|}{ Carbohydrate metabolic process } \\
\hline & CNAG_04245 & Chitinase & 0.621 & 0.562 \\
\hline & CNAG_06501 & 1,3- $\beta$-glucanosyltransferase & 1.101 & 0.140 \\
\hline & CNAG_01239 & Chitin deacetylase & 2.659 & 1.996 \\
\hline & CNAG_02860 & Endo-1,3(4)- $\beta$-glucanase & 3.210 & 1.665 \\
\hline \multicolumn{5}{|c|}{ Protein ubiquitination } \\
\hline & CNAG_01920 & Polyubiquitin & 0.509 & 0.501 \\
\hline \multicolumn{5}{|c|}{ ATP hydrolysis coupled proton transport } \\
\hline & CNAG_05750 & ATPase a subunit & 1.785 & 1.765 \\
\hline \multicolumn{5}{|c|}{ Dephosphorylation } \\
\hline & CNAG_02944 & Acid phosphatase & 0.233 & 0.061 \\
\hline \multicolumn{5}{|c|}{ Oxidation-reduction process } \\
\hline & CNAG_01019 & Cu/Zn superoxide dismutase & 0.350 & 0.142 \\
\hline & CNAG_03465 & Laccase & 1.000 & 0.107 \\
\hline \multicolumn{5}{|l|}{ Proteolysis } \\
\hline & CNAG_00919 & Carboxypeptidase D & 5.770 & 3.708 \\
\hline \multicolumn{5}{|c|}{ Response to stress } \\
\hline & CNAG_01750 & Chaperone & $>10$ & $>10$ \\
\hline \multicolumn{5}{|c|}{ Unknown/Unclassified } \\
\hline & CNAG_04291 & Glycosyl-hydrolase & 0.989 & 0.959 \\
\hline & CNAG_00407 & Glyoxal oxidase & 1.209 & 0.648 \\
\hline & CNAG_06267 & Rds1 protein & 2.834 & 0.518 \\
\hline & CNAG_01653 & Cytokine-inducing glycoprotein & 2.951 & 2.753 \\
\hline & CNAG_04753 & Lactonohydrolase & $>10$ & $>10$ \\
\hline \multicolumn{5}{|l|}{ Hypothetical } \\
\hline & CNAG_06109 & Conserved hypothetical protein & 0.463 & 0.431 \\
\hline & CNAG_05893 & Conserved hypothetical protein & 1.062 & 0.307 \\
\hline & CNAG_05312 & Conserved hypothetical protein & 3.737 & 2.342 \\
\hline
\end{tabular}

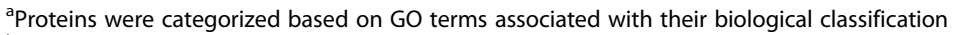

${ }^{b}$ Fold change is reported as the average quantification for $P_{G A L}:: P K A 1$ vs. WT, \pm standard deviation

presence of complex biological samples, such as blood or serum, the retention times between the peptides can shift, impacting the co-elution patterns [33]. We specifically applied MRM to detect Cig1, Aph1, glyoxal oxidase, $\alpha$-amylase, and the novel protein (CNAG_05312) in samples from a macrophage-like cell line and from infected mice.

The samples from the J774A.1 macrophage-like cell line came from cells inoculated with WT and $P_{G A L 7}:$ PKA1 strains under Pka1-repressed (DMEM medium supplemented with glucose) and Pka1-induced (DMEM medium supplemented with galactose) conditions. Intracellular uptake at 2 hpi showed a significant difference in the number of colony forming units (CFUs) per macrophage between the WT and $P_{G A L 7}:: P K A 1$ strains under Pka1-repressed conditions, but not under induced conditions (Fig. 6a). This difference is most likely due to the absence of the capsule for the Pka1-repressed cells, a phenotype that enhances phagocytosis. By $24 \mathrm{hpi}$, rates of intracellular fungal cells per macrophage were significantly different for WT and $P_{\text {GAL7::PKA1 strains under both conditions }}$ (Fig. 6c). Specifically, intracellular rates of infection at 24 


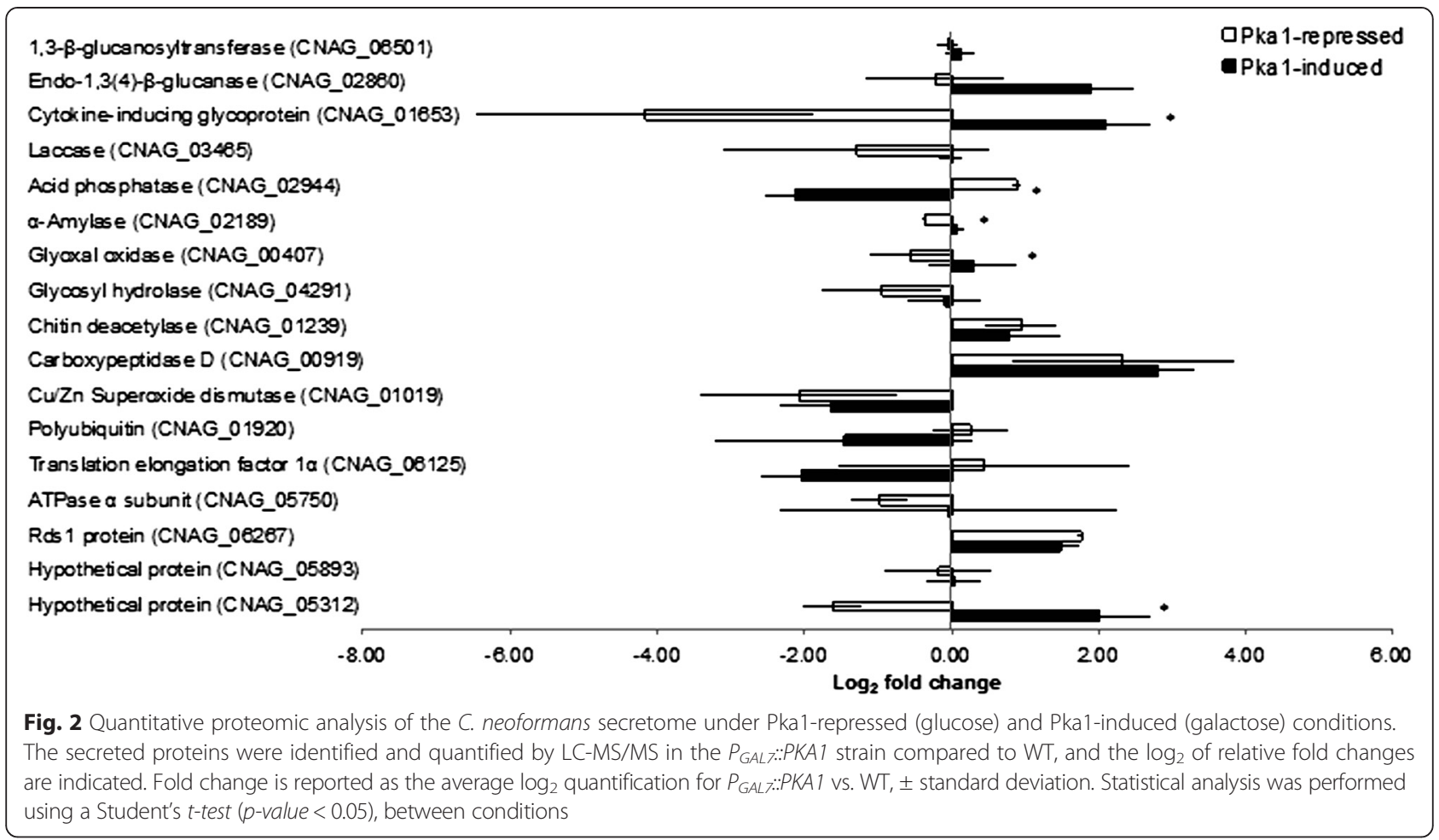

hpi in repressed conditions were $11.49 \pm 2.11 \%$ for the WT and $55.67 \pm 12.76 \%$ for $P_{G A L 7:: P K A 1}$ strains. However, intracellular rates under induced conditions were $9.06 \pm 2.91 \%$ for WT and $1.97 \pm 0.82 \%$ for $P_{G A L 7:: P K A 1}$ strains. Importantly, intracellular uptake rates showed no

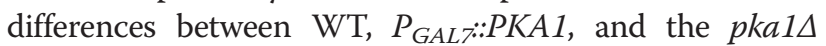
strains under controlled growth conditions (DMEM - high glucose $(0.45 \%))$ at 2 and 24 hpi (Fig. 6b, d). These results indicate that modulation of PKA1 expression influences the intracellular survival of cryptococcal cells.

MRM on macrophage lysates infected with fungal cells at $24 \mathrm{hpi}$ identified the Pka1-regulated and secreted proteins $\alpha$-amylase and glyoxal oxidase in both induced and repressed conditions. Figure 7 shows

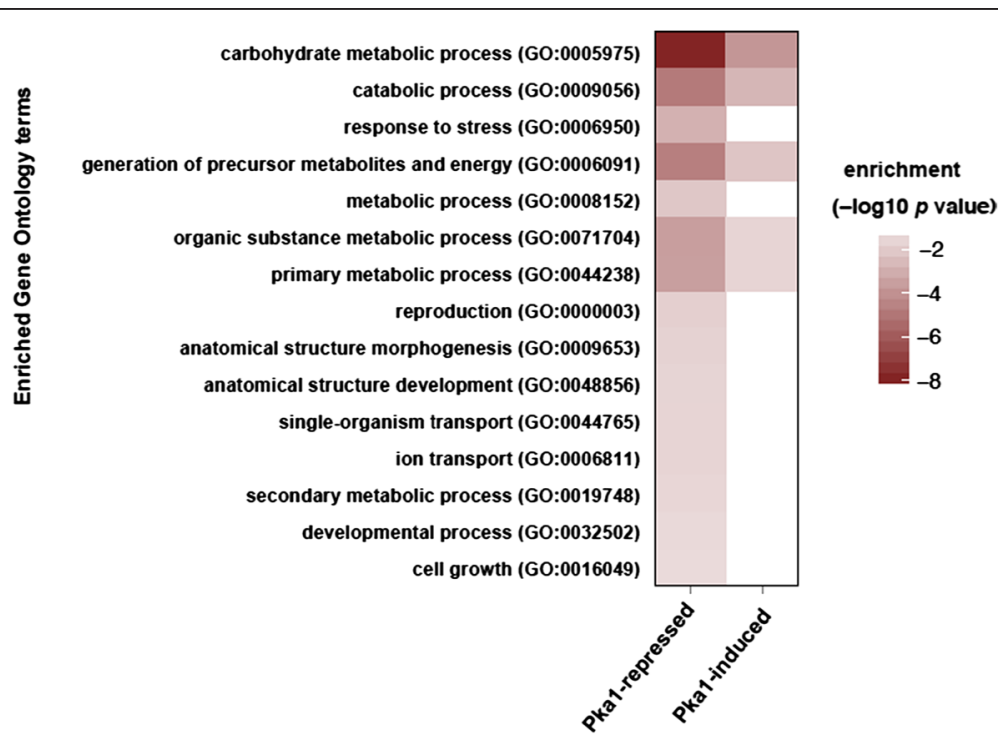

Fig. 3 Enrichment of genes represented in the secretome analysis of cells grown under Pka1-repressed and Pka1-induced conditions compared to all genes present in the WT strain. The enrichment is based on GO terms associated with biological processes 


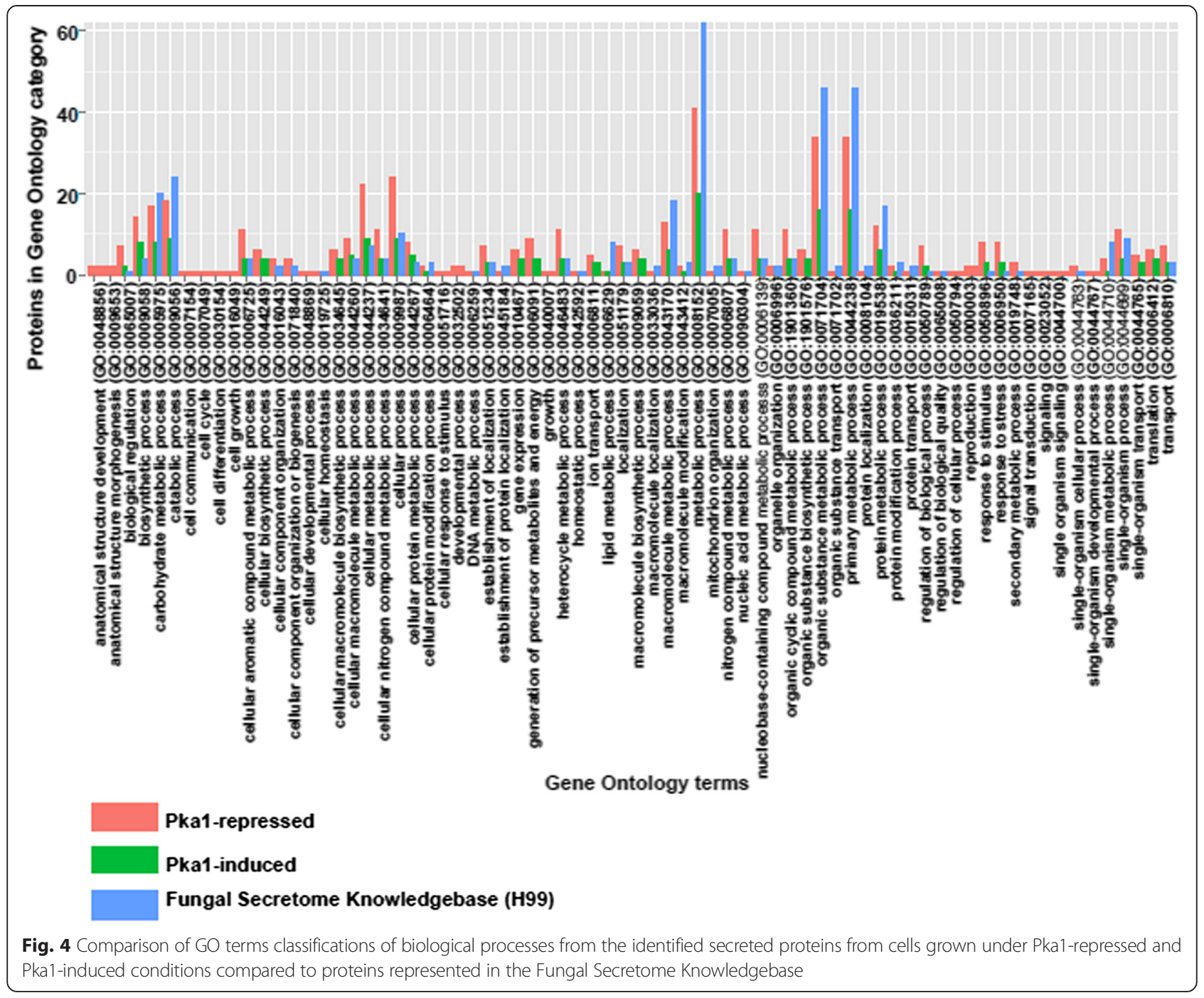

representative chromatographic co-elution patterns of the isotopically-labeled and natural peptides, which allowed for relative quantification of peptides in the replicates of the experiment. For both enzymes, the highest amount of protein was detected in the WT strain in DMEM medium under Pka1-repressed conditions, whereas the $P_{G A L 7:: P K A 1}$ strain under Pka1induction showed the lowest amount of secreted protein. This observation may be associated with reduced intracellular rates of the $P_{G A L 7:: P K A 1}$ strain due to the presence of an enlarged capsule. Overall, we were able to detect $29.8 \pm 37.0 \mathrm{fmol}$ of $\alpha$-amylase and $149.1 \pm 130.0 \mathrm{fmol}$ of glyoxal oxidase in $5 \mu \mathrm{g}$ of total protein from the macrophage lysate following the uptake of $P_{\text {Gal }}:: P K A 1$ under Pka1-induced conditions at 24 hpi.

The samples from infected mice included BAL and blood from animals inoculated with the WT strain.
Three mice were selected for each type of in vivo analysis based on previous studies of cryptococcosis [34-37]. Representative chromatograms of isotopicallylabeled and natural peptides detected in mouse BAL are presented in Fig. 8. The MRM analysis identified Cig1, $\alpha-$ amylase, glyoxal oxidase, and the novel protein (CNAG_05312) in BAL following infection with WT cells. In $5 \mu \mathrm{g}$ of total protein, glyoxal oxidase was the most abundant protein with detection at $779.5 \pm 436.1 \mathrm{fmol}$, followed by the novel protein (CNAG_05312) at $451.0 \pm$ $90.5 \mathrm{fmol}$, Cig1 at $291.3 \pm 54.5 \mathrm{fmol}$, and $\alpha$-amylase with the lowest abundance at $40.1 \pm 9.4 \mathrm{fmol}$. Lastly, we were able to detect Cig1, glyoxal oxidase, and the novel protein (CNAG_05312) in blood. Representative chromatograms of the isotopically-labeled and natural peptides detected in mouse blood are presented in Fig. 9. Again, glyoxal oxidase was the most abundant protein detected at 319.4 \pm $272.7 \mathrm{fmol}$, followed by Cig1 at $62.0 \pm 17.4 \mathrm{fmol}$, and 
Table 4 Bioinformatic analysis of identified and quantified proteins in the secretome of C. neoformans under Pka1-repressed and Pka1-induced conditions

\begin{tabular}{|c|c|c|c|c|c|}
\hline $\begin{array}{l}\mathrm{GO} \\
\text { categories }^{\mathrm{a}} \\
\end{array}$ & $\begin{array}{l}\text { Accession } \\
\text { number }\end{array}$ & Protein name & $\begin{array}{l}\text { Signal peptide } \\
\text { (position) }\end{array}$ & $\begin{array}{l}\text { GPI anchor } \\
\text { (position) }\end{array}$ & Sample preparation \\
\hline \multicolumn{6}{|c|}{ Carbohydrate catabolic process } \\
\hline & CNAG_02189 & a-Amylase & Yes $(21 / 22)$ & Yes (C-26) & EtOH, TCA/acetone \\
\hline \multicolumn{6}{|c|}{ GTP catabolic process } \\
\hline & CNAG_06125 & Translation elongation factor 1 a & No & No & EtOH, TCA/acetone \\
\hline & CNAG_06840 & Translation elongation factor 2 & No & No & TCA/acetone \\
\hline \multicolumn{6}{|c|}{ Carbohydrate metabolic process } \\
\hline & CNAG_00799 & Cellulase & Yes $(22 / 23)$ & No & TCA/acetone \\
\hline & CNAG_01239 & Chitin deacetylase & Yes (18/19) & Yes (C-28) & EtOH, TCA/acetone \\
\hline & CNAG_02860 & Endo-1,3(4)- $\beta$-glucanase & Yes $(22 / 23)$ & No & $\mathrm{EtOH}$ \\
\hline & CNAG_04245 & Chitinase & Yes $(21 / 22)$ & No & EtOH, TCA/acetone \\
\hline & CNAG_05799 & Chitin deacetylase & Yes (18/19) & Yes (C-28) & $\mathrm{EtOH}$ \\
\hline & CNAG_06291 & Deacetylase & Yes $(19 / 20)$ & No & EtOH, TCA/acetone \\
\hline & CNAG_06313 & Phosphoglucomutase & No & No & TCA/acetone \\
\hline & CNAG_06501 & 1,3- $\beta$-glucanosyltransferase & Yes $(20 / 21)$ & Yes (C-6) & EtOH, TCA/acetone \\
\hline
\end{tabular}

Cellular carbohydrate metabolic process

CNAG_03225 Malate dehydrogenase

Trehalose metabolic process

$$
\text { CNAG_03525 }
$$

Trehalase

Glyoxylate metabolic process

$$
\text { CNAG_01137 }
$$

Aconitase

Pentose-phosphate pathway

$$
\begin{aligned}
& \text { CNAG_01984 } \\
& \text { CNAG_07561 }
\end{aligned}
$$

Transaldolase

Phosphogluconate dehydrogenase

Protein ubiquitination

$$
\text { CNAG_01920 Polyubiquitin }
$$

ATP hydrolysis coupled proton transport

$$
\begin{aligned}
& \text { CNAG_05750 } \\
& \text { CNAG_05918 }
\end{aligned}
$$

ATPase a subunit

F0F1 ATP synthase subunit $\beta$

Transmembrane transport

$$
\begin{aligned}
& \text { CNAG_02974 } \\
& \text { CNAG_06101 }
\end{aligned}
$$

Voltage-dependent ion-selective channel

Eukaryotic ADP/ATP carrier

5-methyltetrahydropteroyltriglutamatehomocysteine S-methyltransferase

CNAG_01890

Dephosphorylation

$$
\text { CNAG_02944 }
$$

Acid phosphatase

Glycolysis

CNAG_03072
CNAG_06699

Phosphopyruvate hydratase

Glyceraldehyde-3-phosphate dehydrogenase

Oxidation-reduction process

CNAG_01019
CNAG_03465

$\mathrm{Cu} / \mathrm{Zn}$ superoxide dismutase

Laccase
No

Yes (18/19)

No

No

No

No

No

No

No

No

No

Yes $(16 / 17)$

No

No

No

Yes $(20 / 21)$
No

No

No

No

No

No

No

No

No

Yes (C-25)

No

No

$\mathrm{EtOH}, \mathrm{TCA}$ /acetone

EtOH, TCA/acetone

TCA/acetone

No

No

$\mathrm{EtOH}$

No 
Table 4 Bioinformatic analysis of identified and quantified proteins in the secretome of $C$. neoformans under Pka1-repressed and Pka1-induced conditions (Continued)

Proteolysis

$\begin{array}{ll}\text { CNAG_00581 } & \text { Endopeptidase } \\ \text { CNAG_00919 } & \text { Carboxypeptidase D }\end{array}$

Yes (19/20)

Yes $(21 / 22)$

Response to stress

$\begin{array}{ll}\text { CNAG_00334 } & \text { Heat shock protein } \\ \text { CNAG_01727 } & \text { Hsc70-4 } \\ \text { CNAG_01750 } & \text { Chaperone } \\ \text { CNAG_06150 } & \text { Heat-shock protein 90 }\end{array}$

Translation

CNAG_04021
CNAG_04114
CNAG_06095
CNAG_06605

$60 S$ ribosomal protein L26

405 ribosomal protein 50

Ribosomal protein L13

Ribosomal protein S2

Regulation of transcription

$$
\text { CNAG_00483 }
$$

Actin

Nucleosome assembly

$$
\text { CNAG_06746 }
$$

Histone h2b

Unknown/Unclassified

CNAG_00407
CNAG_00776
CNAG_01653
CNAG_02030
CNAG_02850
CNAG_02864
CNAG_02943
CNAG_04291
CNAG_04753
CNAG_06267

Glyoxal oxidase

Immunoreactive mannoprotein MP88

Cytokine-inducing glycoprotein

Glyoxal oxidase

Glucan endo-1,3-a-glucosidase agn1

Predicted protein

Cytoplasmic protein

Glycosyl-hydrolase

Lactonohydrolase

Rds1 protein

Hypothetical

$\begin{array}{ll}\text { CNAG_00586 } & \text { Conserved hypothetical protein } \\ \text { CNAG_00587 } & \text { Conserved hypothetical protein } \\ \text { CNAG_00588 } & \text { Conserved hypothetical protein } \\ \text { CNAG_01047 } & \text { Conserved hypothetical protein } \\ \text { CNAG_01562 } & \text { Conserved hypothetical protein } \\ \text { CNAG_03007 } & \text { Conserved hypothetical protein } \\ \text { CNAG_03223 } & \text { Conserved hypothetical protein } \\ \text { CNAG_03492 } & \text { Conserved hypothetical protein } \\ \text { CNAG_05312 } & \text { Conserved hypothetical protein } \\ \text { CNAG_05595 } & \text { Conserved hypothetical protein } \\ \text { CNAG_05893 } & \text { Conserved hypothetical protein } \\ \text { CNAG_06109 } & \text { Conserved hypothetical protein }\end{array}$

No

No

No

No

No

No

No

No

No

No

Yes $(16 / 17)$
Yes $(22 / 23)$
Yes $(19 / 20)$
Yes $(21 / 22)$
Yes $(21 / 22)$
Yes $(16 / 17)$
No
Yes $(17 / 18)$
No
Yes $(20 / 21)$

Yes $(16 / 17)$

Yes (23/24)

Yes $(19 / 20)$

Yes $(16 / 17)$

Yes $(19 / 20)$

Yes (18/19)

No

Yes $(19 / 20)$

Yes $(19 / 20)$

Yes $(19 / 20)$

Yes (18/19)

Yes $(16 / 17)$

No

No
No

No

No

No

No

No

No

No

No

No

No

No

Yes (C-27)

Yes (C-30)

No

Yes (C-32)

Yes (C-26)

No

No

Yes (C-31)

No

Yes

TCA/acetone

$\mathrm{EtOH}, \mathrm{TCA} /$ acetone

TCA/acetone

$\mathrm{EtOH}$

$\mathrm{EtOH}, \mathrm{TCA} /$ acetone

TCA/acetone

TCA/acetone

TCA/acetone

$\mathrm{EtOH}$

TCA/acetone

TCA/acetone

TCA/acetone

EtOH, TCA/acetone

TCA/acetone

$\mathrm{EtOH}$

EtOH, TCA/acetone

TCA/acetone

TCA/acetone

TCA/acetone

$\mathrm{EtOH}$

EtOH, TCA/acetone

$\mathrm{EtOH}$, TCA/acetone

EtOH, TCA/acetone

TCA/acetone

$\mathrm{EtOH}$

EtOH, TCA/acetone

$\mathrm{EtOH}$

$\mathrm{EtOH}$

$\mathrm{EtOH}$

TCA/acetone

$\mathrm{EtOH}, \mathrm{TCA} /$ acetone

TCA/acetone

$\mathrm{EtOH}, \mathrm{TCA} /$ acetone $\mathrm{EtOH}$

\footnotetext{
aproteins were categorized based on GO terms associated with their biological classification

${ }^{\mathrm{b}}$ The presence of a signal peptide was determined using SignalP, Phobius, and Signal-3 L

${ }^{\mathrm{C}}$ The presence of a signal peptide was determined using GPI-SOM
} 


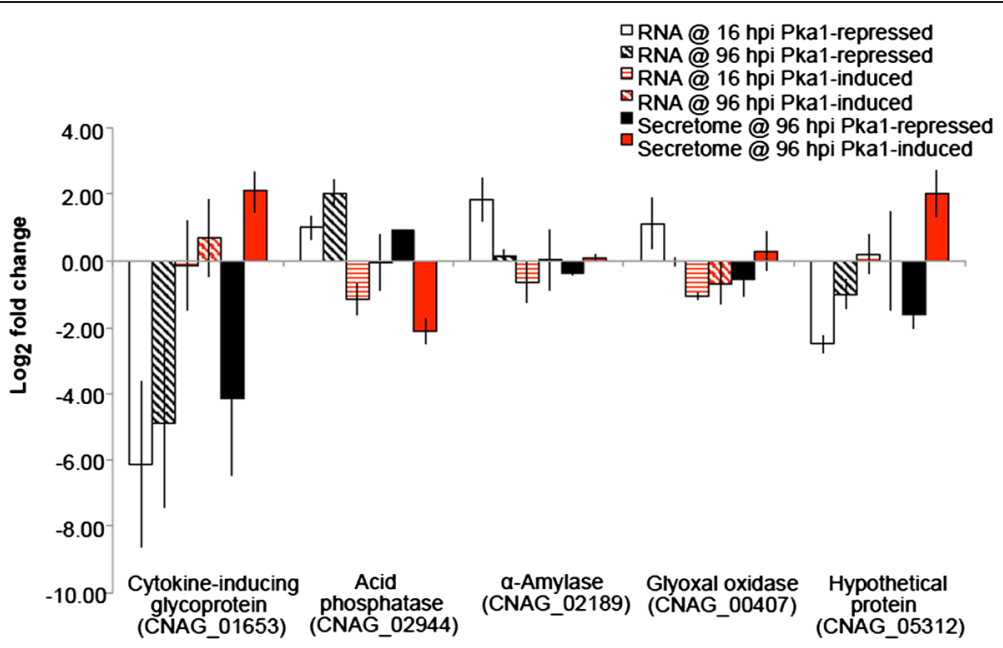

Fig. 5 Comparison of RNA expression levels using qRT-PCR to analyze samples from cells at 16 and 96 hpi, versus secreted protein abundance using quantitative proteomics at 96 hpi under Pka1-repressed and Pka1-induced conditions. The samples were evaluated in triplicate, and values are reported as average $\log _{2}$ quantification \pm standard deviation

the novel protein (CNAG_05312) at $3.1 \pm 3.8 \mathrm{fmol}$ in $5 \mu \mathrm{g}$ of total protein. Aph1 levels were below the limit of detection in all samples. Taken together, our targeted proteomics approach identified and quantified the Pka1-regulated secreted proteins as potential biomarkers following host challenge with cryptococcal cells.

\section{Discussion}

The secretion of extracellular enzymes and virulenceassociated factors is important for the proliferation and survival of pathogens in the host environment. For the pathogenic yeast $C$. neoformans, virulence depends to a large extent on the export of polysaccharide to form a capsule, as well as targeted delivery of laccase to the cell wall for deposition of melanin, and secretion of extracellular enzymes [23, 24, 28, 38]. The cyclic-AMP/Protein Kinase A signal transduction pathway plays a key role in regulating these processes but the underlying mechanisms remain to be understood in detail $[16,17]$. We therefore used a $P_{G A L 7:: P K A 1}$ strain under Pka1repressed and Pka1-induced conditions in this study to investigate the influence of Pka1 on the secretome of $C$. neoformans. Quantitative proteomics allowed us to identify 61 different proteins in the secretome including a subset of five whose abundance was regulated by Pka1. These five proteins include a cytokine-inducing glycoprotein (Cig1), an $\alpha$-amylase, a glyoxal oxidase, an acid phosphatase (Aph1), and a novel protein (CNAG_05312). We also observed a change in the secretome profile upon induction of PKA1 expression thus establishing a view of the impact of PKA activity on the extracellular protein composition. In general, this analysis highlighted the enrichment of Pka1-regulated biological processes in the secretome, revealed potential targets for conventional and non-conventional modes of secretion, and provided candidate biomarkers for investigating cryptococcosis.

\section{Modulation of PKA1 expression leads to a change in the secretome}

Our analysis revealed a change in the abundance of secreted C. neoformans proteins associated with glycolysis, translational regulation, nucleosome assembly, and stress response over a time course from 16 to $120 \mathrm{~h}$. We speculate that some of these proteins may result from packaging in vesicles known to transit through the cell wall and accumulate in the extracellular environment $[24,39]$. In this case, modulation of PKA activity may indirectly influence the proteome of vesicles as a reflection of an impact on the intracellular proteome. This idea is supported by our observed influence of PKA1 modulation on the abundance of the translation machinery because ribosomal proteins, in particular, are abundant in extracellular vesicles [39]. It is also well known that PKA influences the transcription of ribosomal protein genes in other organisms and this influence is conserved in $C$. neoformans $[22,40]$. Our analysis of the intracellular proteome also revealed suppression of ribosomal cellular protein abundance upon induction of Pka1 (Geddes et al., unpublished data). We also observed a connection between Pka1 activation and the abundance of glycolytic proteins. This is interesting in light of previous reports demonstrating the importance of glycolysis for virulence and the persistence of $C$. neoformans in the cerebral spinal fluid [41]. These findings are consistent with a previous analysis of the transcriptome, which showed that Pka1 influences the levels of transcript for genes involved in glycolysis [22]. Furthermore, the observed influence of Pkal induction on the secretion of proteins 

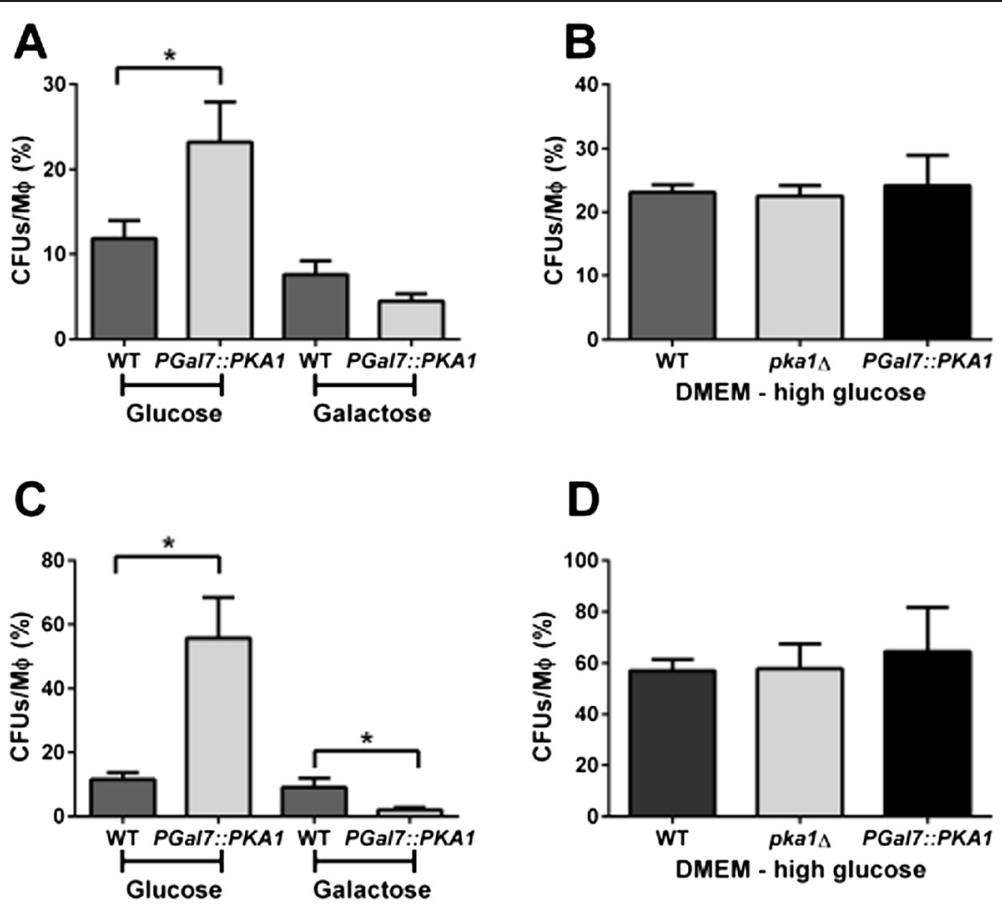

Fig. 6 Interactions of WT and Pka1-regulated strains with J774A.1 murine macrophages. a Intracellular rate at 2 hpi of WT and $P_{\text {GAL }}:$ PKA1 strains grown under Pka1-repression (glucose) and Pka1-induction (galactose). b As a control, the colony forming units (CFUs) per macrophage grown in standard DMEM medium (containing $0.45 \%$ glucose) are presented. c Rate of intracellular fungal cell per macrophage at 24 hpi of WT and $P_{\text {GAL }}$ :PKA1 strains grown under Pka1-repression (glucose) and Pka1-induction (galactose). $\mathbf{d}$ The CFUs per macrophage grown in standard DMEM medium (containing $0.45 \%$ glucose) are presented as a control. The experiments were performed in triplicate; the average percent of survival was reported \pm standard error of the mean. For statistical analysis, an unpaired $t$-test with Welch's correction ( $p$-value $<0.05)$ was performed between conditions (* denotes significant difference). The samples at 24 hpi were employed for the analysis of protein abundance shown in Fig. 7

associated with stress response is consistent with observed Pka1 regulation at the transcriptional level. In this context, we identified a heat shock protein 70 (Hsc70-4), which is associated with the response to stress and which was previously localized to the cell surface of $C$. neoformans [42]. The observed connection between the stress response and Pka1 induction may indicate coordination for facilitation of fungal survival and proliferation during colonization of vertebrate hosts.

\section{Pka1 regulation of mannoproteins and cell wall functions:} connections with Rim101

The influence of PKA on the abundance of the mannoprotein Cig1 is of particular interest because we previously showed that its transcript is one of the most abundant in cells grown in low iron medium [43]. In addition, the protein is important for iron acquisition from heme and virulence in C. neoformans [44]. We found that the extracellular abundance of Cig1 increased upon induction of Pka1 and that transcript levels and protein abundance were well correlated. CIG1 is positively regulated by the $\mathrm{pH}$-responsive transcription factor Rim101, which in turn is activated by the cAMP/ PKA pathway [45]. Therefore, the regulation of CIG1
mRNA and Cig1 protein levels observed upon induction of Pka1 likely reflect regulation by Rim101. This finding is consistent with recent discoveries that Rim101 controls cell wall composition and capsule attachment via an influence on the expression of cell wall biosynthetic genes [46, 47].

In general, a number of proteins associated with cell wall synthesis and integrity, pathogenesis and the immune response were prominent in the secretome of $C$. neoformans upon modulation of $P K A 1$ expression. These proteins included an endo-1,3(4)- $\beta$ glucanase and a 1,3$\beta$-glucanosyltransferase, both of which have been previously identified in studies of the extracellular proteomes of $C$. neoformans and other fungal pathogens such as Histoplasma capsulatum [28, 48-51]. Endo-1,3(4)- $\beta$ glucanase is located in the surface layers of the cell wall or in the capsule and has roles in metabolism, autolysis, and cell separation $[50,52]$. The $1,3-\beta$-glucanosyltransferase is described as a glycolipid protein anchored to the cell membrane in yeasts and may have a role in virulence [53]. Our proteomic analysis also identified chitin deacetylases associated with the formation of chitin and cell wall integrity, and the enzyme laccase, which is responsible for melanin deposition in the cell wall and 

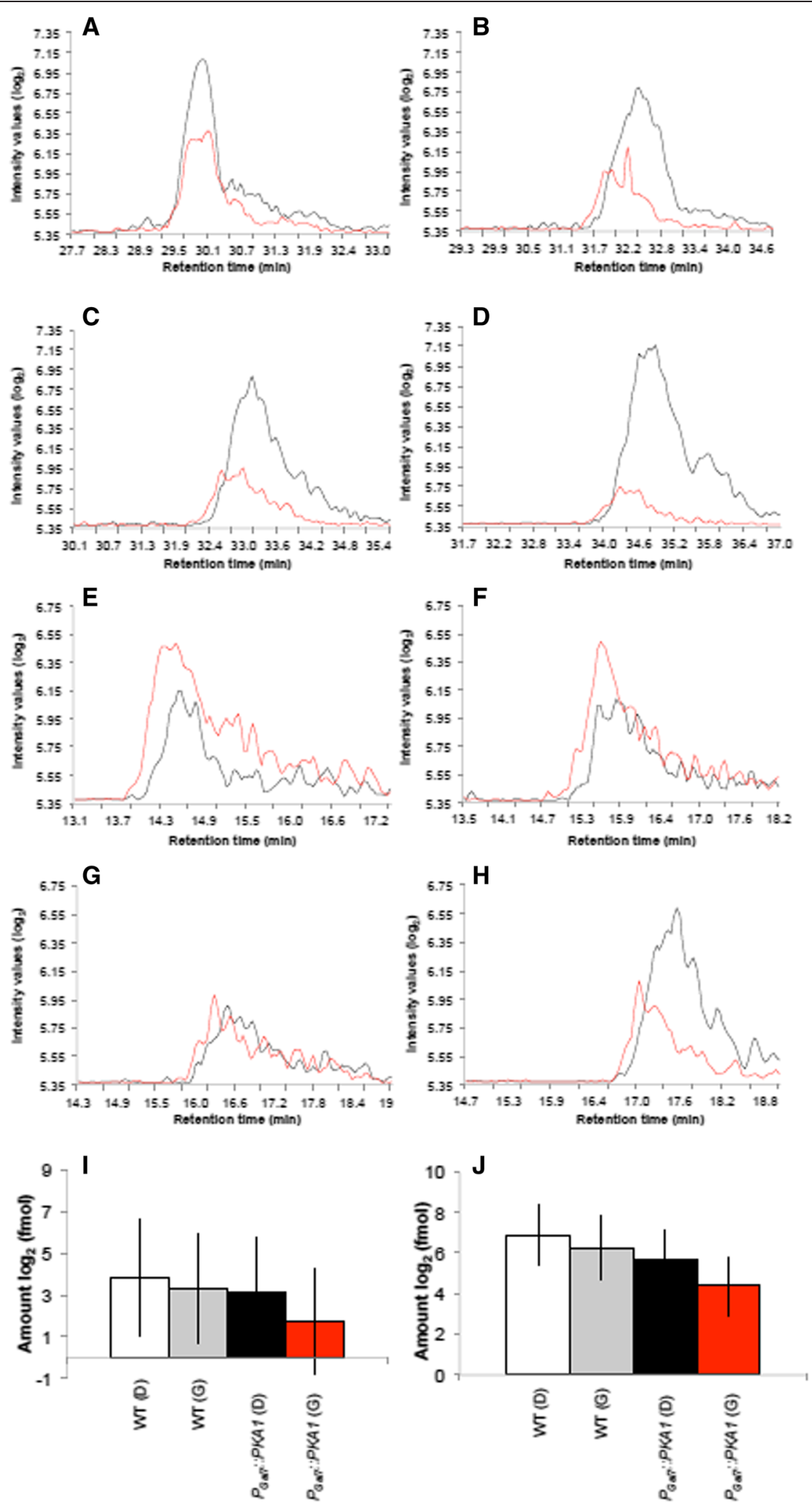

Fig. 7 (See legend on next page.) 
(See figure on previous page.)

Fig. 7 Detection of Pka1-regulated proteins in lysates of macrophage-like cells containing C. neoformans. Chromatographic representation of the most abundant peptide and its transition for a-amylase (CNAG_02189) identified from isotopically-labeled peptide or natural peptide for each of the following samples: a macrophage lysate challenged with WT cells grown in $0.2 \%$ glucose; (b) macrophage lysate challenged with WT cells grown in $0.2 \%$ galactose; (c) macrophage lysate challenged with $P_{\text {GAL }}:$ PKA1 cells grown in $0.2 \%$ glucose; (d) macrophage lysate challenged with $P_{\text {GAL }}:$ :PKA1 cells grown in galactose $0.2 \%$. Chromatographic representation of the most abundant peptide and its transition for glyoxal oxidase (CNAG_00407) identified from isotopically-labeled peptide or natural peptide for each of the following samples: (e) macrophage lysate challenged with WT cells grown in $0.2 \%$ glucose; (f) macrophage lysate challenged with WT cells grown in $0.2 \%$ galactose; (g) macrophage lysate challenged with $P_{\text {GAL }}::$ PKA1 cells grown in $0.2 \%$ glucose; (h) macrophage lysate challenged with $P_{\text {GAL }}:$ PKA1 cells grown in $0.2 \%$ galactose. Black indicates isotopically-labeled peptide; red indicates natural peptide. i Quantification of a-amylase identified in the macrophage lysates was based on the area under the curve for the isotopically-labeled peptide versus the natural peptide in WT and PGAL ::PKA1 strains under Pka1-repressed (d) and Pka1-induced (g) conditions. The avergae ( \pm S.D.) amount of peptide present in the sample is reported. $\mathbf{j}$ Quantification of glyoxal oxidase identified in the macrophage lysates was based on the area under the curve for the isotopically-labeled peptide versus the natural peptide in WT and $P_{\text {GAL }}:$. PKA1 strains under Pka1-repressed (D) and Pka1-induced (G) conditions. The avergae ( \pm S.D.) amount of peptide present in the sample is reported. Five micrograms of total protein were used for the assays and all assays were performed in triplicate

influences cryptococcal virulence [28, 51, 54-57]. These findings are consistent with our previous transcriptomic analysis, which revealed an influence of PKA on the expression of cell wall associated genes [22].

We also identified a novel protein (CNAG_05312) with a pattern of mRNA and protein regulation by Pka1 activity that was quite similar to that of Cig1. This novel protein contains a predicted carbohydrate-binding domain and was annotated as a macrophage-activating glycoprotein (reminiscent of the cytokine-inducing glycoprotein designation of Cig1). These observations suggest that further investigation is warranted for this protein in the context of iron acquisition and virulence. This idea is reinforced by the finding that Rim101 also positively regulates expression of the CNAG_05312 gene [45]. Interestingly, the CNAG_05312 gene is also regulated at the transcript level by the transcription factor Gat201 that, like Pka1, influences capsule size, virulence, and uptake by macrophages [58, 59]. Considering these similar phenotypes, it is possible that Gat201 and Pka1/ Rim101 both regulate the expression of the CNAG_05312 protein and subsequently influence the activation of macrophages during infection. Overall, our investigation of the secretome reinforced connections between modulation of Pka1 activity, Rim101 and cell wall integrity, and it revealed an impact of PKA on the extracellular abundance of proteins with known (Cig1) and potential (the novel CNAG_05312 protein) influences on virulence.

\section{Pka1 influences the secretion of a-amylase and glyoxal oxidase enzymes}

Pka1 also positively regulated the abundance in the secretome of an $\alpha$-amylase and a glyoxal oxidase which were previously identified in the extracellular proteome of C. neoformans [28, 51]. Amylases are associated with carbohydrate metabolism, particularly starch degradation for energy production [60]. In C. neoformans, the secretion of amylases in the PKA-regulated strains was reported previously and we were able to measure and confirm $\alpha$-amylase activity in the extracellular medium [29]. Glyoxal oxidases are extracellular $\mathrm{H}_{2} \mathrm{O}_{2}$-producing enzymes associated with cellulose metabolism [61]. There is evidence that glyoxal oxidase activity is involved in filamentous growth and pathogenicity of Ustilago maydis, as well as fertility in Cryptococcus gattii [61, 62]. A similar pattern in response to PKA1 expression was observed upon comparison of the transcript and protein levels for both the $\alpha$-amylase and the glyoxal oxidase. A direct correlation between transcript levels and protein abundance was not as evident as for Cig1. This could potentially be due to post-transcriptional regulation, differences in mRNA and protein half-lives and issues with timing [63]. It is also possible that PKA may regulate additional processes to influence extracellular protein abundance, such as the activity of the secretory pathway. Overall, the secretome data revealed a new connection between PKA regulation and the $\alpha$-amylase and glyoxal oxidase enzymes, and this discovery indicates that further analysis of their potential roles in virulence is warranted.

\section{Pka1 influences the secretion of the virulence-associated acid phosphatase, Aph1}

The extracellular abundance of the acid phosphatase Aph1 and its transcript levels were negatively regulated by induction of PKA1 expression thus revealing an opposite pattern of regulation compared with the other four genes. Phosphatases have been predicted to have roles in cell wall biosynthesis, cell signaling, phosphate scavenging, and in adhesion of $C$. neoformans to epithelial cells $[24,28,64-67]$. The APH1 gene was recently characterized and its expression was found to be induced by phosphate limitation; the Aph1 protein was also the major conventionally secreted acid phosphatase in C. neoformans [28]. Aph1 was also shown to hydrolyze a variety of substrates to potentially scavenge phosphate from the environment, and an aph1 deletion mutant had a slight virulence defect in both Galleria 

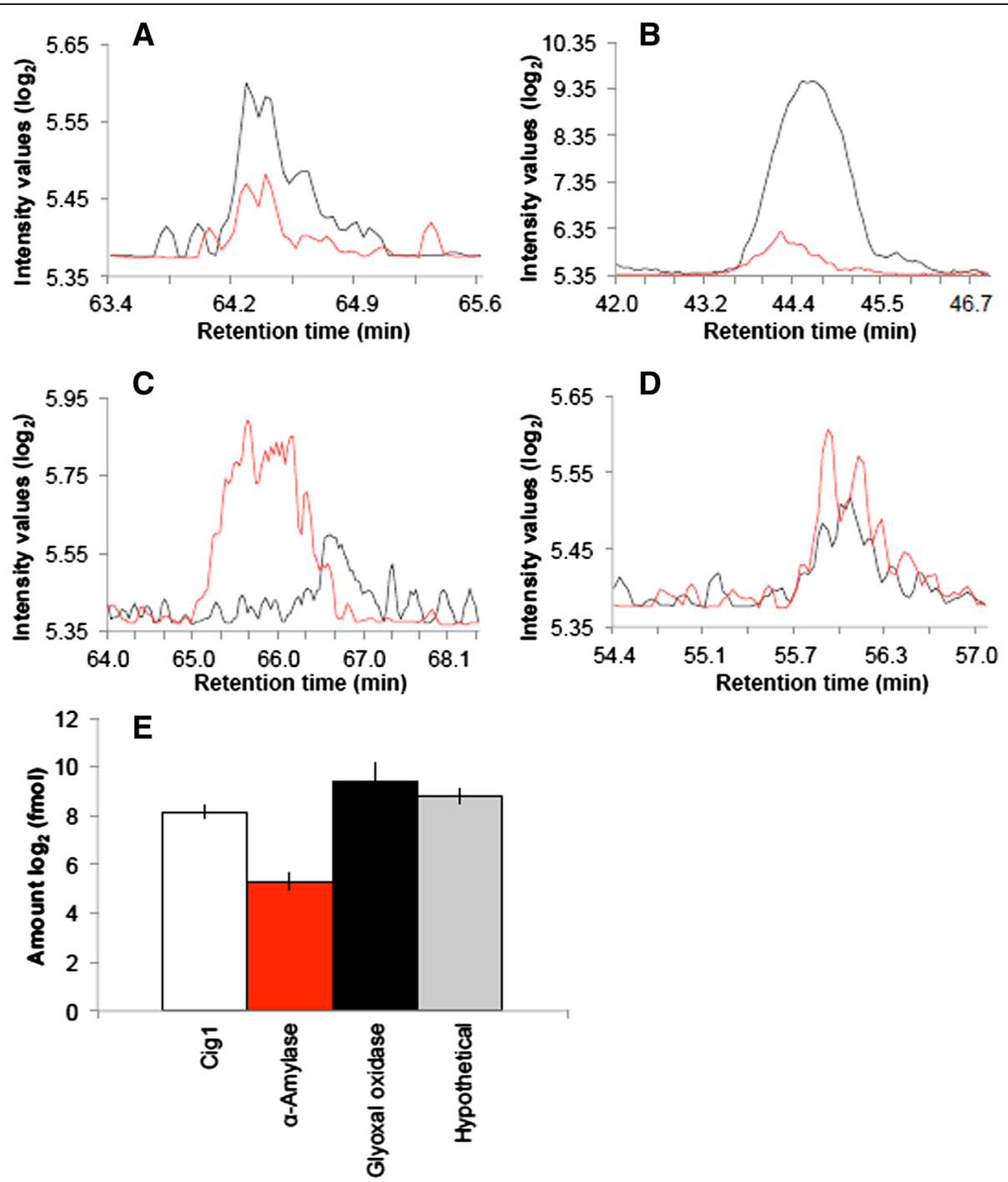

Fig. 8 Detection of Pka1-regulated proteins in mouse bronchoalveolar lavage samples. Chromatographic representation of the most abundant peptide and its transition identified from isotopically-labaled peptide or natural peptide for each of the following proteins: (a) Cig1 (CNAG_01653), (b) a-Amylase (CNAG_02189), (c) Glyoxal oxidase (CNAG_00407), (d) Hypothetical protein (CNAG_05312). Black indicates isotopically-labeled peptide; red indicates natural peptide. e Quantification of proteins identified in the mouse BAL samples based the area under the curve for the isotopically-labeled peptide versus the natural peptide, for Cig1, a-amylase, glyoxal oxidase, and hypothetical (CNAG_05312) proteins. The avergae ( \pm S.D.) amount of peptide present in the sampleis reported. Five micrograms of total protein were used for the assays and all assays were performed in triplicate

mellonella and mouse models of cryptococcosis. The latter phenotype is consistent with our recent study showing that a high affinity phosphate uptake system is required for growth on low-phosphate medium, for formation of the virulence factors melanin and capsule, for survival in macrophages, and for virulence in mice [68]. This study also revealed that defects in PKA influence the growth of $C$. neoformans on phosphate-limited medium. Our discovery of PKA regulation of Aph1 abundance in the secretome therefore further reinforces a connection between phosphate acquisition and PKA regulation associated with virulence.
PKA regulation and the intersection of secretome studies in C. neoformans

Our profiling of the secretome upon modulation of Pka1 activity confirmed the presence of previously identified extracellular and vesicular proteins, including those associated with virulence and fungal survival within the host, as well as novel secreted proteins. We identified the classically secreted C. neoformans protein, laccase, associated with fungal virulence, but other proteins such as urease and phospholipase B were not identified in our study. Their absence could be attributed to growth conditions, precipitation methods, supernatant collection 

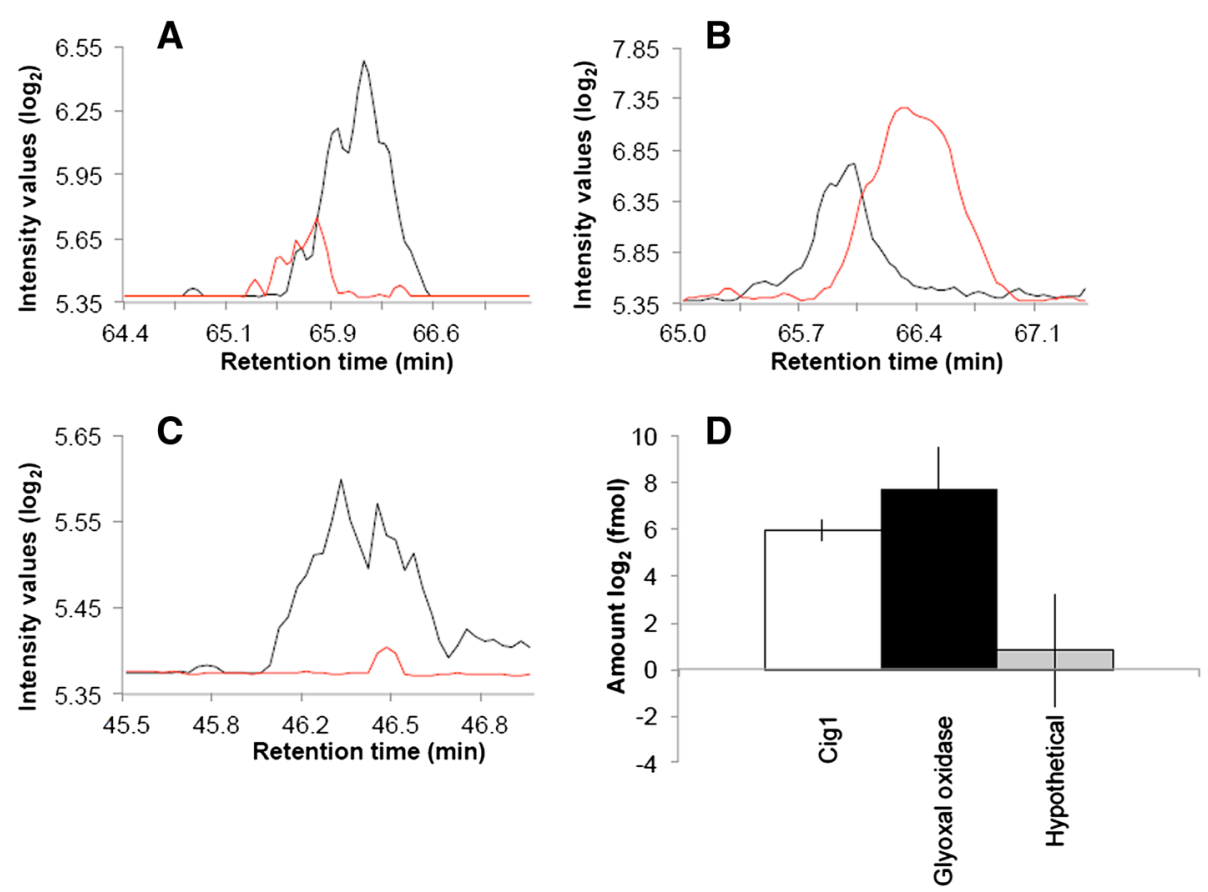

Fig. 9 Detection of Pka1-regulated proteins in mouse blood samples. Chromatographic representation of the most abundant peptide and its transition identified from isotopically-labaled peptide or natural peptide for each of the following proteins: (a) Cig1 (CNAG_01653), (b) Glyoxal oxidase (CNAG_004070), (c) Hypothetical protein (CNAG_05312). Black indicates isotopically-labeled peptide; red indicates natural peptide. d Quantification of proteins identified in the mouse blood samples based the area under the curve for the isotopically-labeled peptide versus the natural peptide, for Cig1, glyoxal oxidase, and hypothetical (CNAG_05312) proteins. The average ( \pm S.D.) amount of peptide present in the sample is reported. Five micrograms of total protein were used for the assays and all assays were performed in triplicate

times, and relative abundance in the secretome. A recent proteome study that removed free capsular polysaccharide from the extracellular environment identified 105 secreted proteins and a direct comparison with our study showed an overlap of $52 \%$ [28]. Previous investigation of the proteins in extracellular vesicles of $C$. neoformans also showed an overlap of nearly $56 \%$ with proteins identified in our study [24, 39]. This overlap is primarily associated with proteins not typically expected in the secretome. For example, ATP subunits/carriers, translation elongation factor, actin, and multiple ribosomal proteins were identified and their presence was attributed to packaging in extracellular vesicles, and not necessarily due to direct secretion. In the absence of an N-terminal signal peptide, proteins may be exported via nonconventional secretion. This may include the use of membrane-bound, extracellular vesicles capable of traversing the cell wall, the possible fusion of multi-vesicular bodies with the plasma membrane, or the capture of cytosolic material to form vesicles (blebbing), as discussed above [23, 24, 69-72]. Taken together, our profile of secreted proteins in $C$. neoformans is in agreement with previous secretome studies. However, our ability to modulate Pka1 activity provides an opportunity to identify novel proteins in the extracellular environment as well as identify proteins specifically regulated by Pka1. This approach led to the unique identification of the novel secreted protein (CNAG_05312) that was specifically associated with modulation of Pka1 activity and not found in other proteomic studies.

\section{Detection of potential biomarkers during cryptococcal infection}

Biomarkers are indicators of normal or pathogenic processes as well as the efficacy of therapy [73]. In this regard, targeted detection of secreted cryptococcal proteins provides an opportunity to identify potential biomarkers for early diagnosis of infection and to monitor antifungal therapy. Early and rapid diagnosis remains limited for systemic fungal infections, such as those caused by Candida and Aspergillus species, as well as $C$. neoformans and $C$. gattii [74]. Biomarkers of infection by specific fungal species would therefore be valuable for identification and for precise measurements of fungal burden. A recent study using the presence of the cell wall component galactomannan in BAL as a diagnostic tool for invasive fungal disease highlights an opportunity for biomarker discovery in fungal pathogens [75]. Additionally, the use of targeted proteomics (and MRM in particular) is a novel approach to study the secretion of virulence factors in $C$. 
neoformans, particularly in the context of signaling functions like PKA that sense conditions relevant to the host environment.

The secreted proteins that we identified to be regulated in abundance by Pkal provide an opportunity to develop diagnostic biomarkers that are also informative about signaling via the cAMP/PKA pathway in vitro and during infection. For example, Cig1 is an important candidate biomarker given its abundance in iron-starved cells and its role in virulence through iron acquisition and uptake. Our ability to detect Cig1 in the blood and BAL fluid of infected animals confirms its expression and establishes the protein as a potential biomarker. These findings may also indicate a role for Cig1 in iron uptake in these environments although, interestingly, we did not detect Cig1 in macrophage lysates. Based on our observed differences in intracellular replication, Pka1 seems to impact the intracellular environment of macrophages. In this regard, we did detect the glyoxal oxidase and $\alpha$-amylase proteins by MRM in macrophages containing cryptococcal cells. Expression of these proteins has not previously been reported during interactions with macrophages, although the production of $\mathrm{H}_{2} \mathrm{O}_{2}$ and induction of oxidative stress via glyoxal oxidase could potentially influence intracellular survival. It is known that oxidative stress induces autophagy in macrophages and can impair phagocytic activity [76, 77]. Additionally, loss of an $\alpha$-amylase in $H$. capsulatum attenuated the ability of the fungus to kill macrophages and to colonize murine lungs [78]. This influence appeared to be related to the ability to produce $\alpha-(1,3)$ glucan. The regulation of glyoxal oxidase and $\alpha$-amylase by Pka1 activity and their detection in macrophage lysates suggests that it would be interesting to examine the roles of these enzymes in intracellular survival and virulence. Our approach with MRM is also informative about tissue specific expression of fungal proteins during disease. In addition to the examples described above, we found that colonization of murine lungs resulted in secretion of $\alpha$-amylase, glyoxal oxidase and the novel protein from gene CNAG_05312. The novel protein was also found in blood and, given its similar regulation with Cig1 these results suggest future studies on the role of this protein in iron acquisition and virulence.

\section{Conclusion}

In this study we characterized the overall impact of PKA1 modulation on the secretome and discovered five proteins regulated by Pka1. The identified proteins had known roles associated with cell wall functions, fungal survival within the host, and virulence. Our identification of a novel protein with potential roles in iron uptake and virulence also suggested a previously unknown connection between Pka1 and Gat201. We were also able to detect Pka1-regulated secreted proteins in biological samples as potential biomarkers, providing a new opportunity for diagnosing fungal infection and monitoring disease progression.

\section{Methods}

\section{Fungal strains and culture conditions}

The C. neoformans var. grubii wild-type strain H99 (WT) and the $P_{G A L 7 \%: P K A 1}$ strain with galactoseinducible/glucose repressible expression of PKA1 were used for this study $[16,29]$. The strains were maintained on yeast extract peptone dextrose (YPD) medium (1\% yeast extract, $2 \%$ peptone, $2 \%$ dextrose, and $2 \%$ agar). For studies involving regulation of PKA1, cells of the WT and regulated strains were pre-grown overnight with agitation at $30{ }^{\circ} \mathrm{C}$ in YPD broth, transferred to yeast nitrogen base medium with amino acids (YNB, SigmaAldrich) and incubated overnight with agitation at $30{ }^{\circ} \mathrm{C}$. Cell counts were performed and $5 \times 10^{7}$ cells $/ \mathrm{ml}$ were transferred to Minimal Medium (MM) (29.4 mM $\mathrm{KH}_{2} \mathrm{PO}_{4}, 10 \mathrm{mM} \mathrm{MgSO} 4 \cdot 7 \mathrm{H}_{2} \mathrm{O}, 13 \mathrm{mM}$ glycine, $3 \mu \mathrm{M}$ thiamine, $0.27 \%$ carbon source) containing either glucose $(M M+D)$ or galactose $(M M+G)$. For end-point studies, cells were incubated with agitation at $30{ }^{\circ} \mathrm{C}$ in $\mathrm{MM}+\mathrm{D}$ or $\mathrm{MM}+\mathrm{G}$ for $96 \mathrm{~h}$; for time-course studies, cells were incubated with agitation at $30{ }^{\circ} \mathrm{C}$ in $\mathrm{MM}+\mathrm{D}$ or $\mathrm{MM}+\mathrm{G}$ for $16,48,72$, and $120 \mathrm{~h}$. Time points were selected based on previous studies on the timing of protein secretion as well as the analysis of proteins in extracellular vesicles of $C$. neoformans, which used samples collected at 48 and $72 \mathrm{~h}$ of growth [23, 24, 64]. Samples were collected in triplicate for analysis.

\section{Protein quantification, precipitation and in-solution digestion}

To collect supernatant samples, cells were removed by centrifugation at 3,500 rpm for $15 \mathrm{~min}$ at $4{ }^{\circ} \mathrm{C}$ and the culture medium was transferred to new tubes; this step was repeated four times until all cell debris had been removed. Supernatant samples were kept on ice and total protein concentration was measured by a BCA-Proteinassay (Pierce). Ultrapure bovine serum albumin was used as a calibration standard. In addition to using two approaches for protein precipitation as described below, we also used a combination of sample collection time points (time-point and end-point analyses) to maximize protein detection and obtain a comprehensive view of the secretome. The first approach involved a timecourse study in which a stringent trichloroacetic acid (TCA)/acetone precipitation was performed [79]. In brief, an aliquot of culture supernatant $(50 \mu \mathrm{g}$ total protein) was mixed with five volumes of ice-cold TCA/acetone $(20 \% / 80 \% \mathrm{w} / \mathrm{v})$ and incubated overnight at $-20{ }^{\circ} \mathrm{C}$. Precipitated proteins were collected by centrifugation 
at $10,000 \mathrm{rpm}$ for $20 \mathrm{~min}$ at $4{ }^{\circ} \mathrm{C}$. The pellet was washed four times with ice-cold acetone, air-dried and stored at $-20{ }^{\circ} \mathrm{C}$. The second approach, which was less stringent than the TCA/acetone method, was used for the end-point studies and involved ethanol $(\mathrm{EtOH}) /$ acetate precipitation [80]. In brief, an aliquot of culture supernatant $(50 \mu \mathrm{g}$ total protein) was diluted with 4 volumes of absolute EtOH, $2.5 \mathrm{M} \mathrm{NaCH}_{3} \mathrm{COO}$ was used to bring the solution to $50 \mathrm{mM} \mathrm{NaCH}_{3} \mathrm{COO}$, pH 5.0 and $20 \mu \mathrm{g}$ of glycogen was added to the sample. Samples were vortexed and incubated at room temperature for $2 \mathrm{~h}$ with periodic agitation. Precipitated proteins were collected by centrifugation at 15,000 rpm for $10 \mathrm{~min}$ at $4{ }^{\circ} \mathrm{C}$. The pellet was washed twice with $\mathrm{EtOH}$, then air-dried and stored at $-20{ }^{\circ} \mathrm{C}$. All supernatant samples were subjected to in-solution digestion using ACS grade chemicals or HPLC grade solvents (Thermo Scientific and Sigma-Aldrich) [81]. In brief, the precipitated protein pellet was solubilized in digestion buffer (1\% sodium deoxycholate, $50 \mathrm{mM}$ $\mathrm{NH}_{4} \mathrm{HCO}_{3}$ ), incubated at $99{ }^{\circ} \mathrm{C}$ for 5 min with agitation, followed by reduction $(2 \mathrm{mM}$ of dithiothreitol (DTT) for $25 \mathrm{~min}$ at $56{ }^{\circ} \mathrm{C}$ ), alkylation $(4 \mathrm{mM}$ of iodoacetamide (IAA) for $30 \mathrm{~min}$ at room temperature in the dark), and trypsinization $(0.5 \mu \mathrm{g} / \mu \mathrm{l}$ of sequencing grade modified trypsin (Promega)) overnight at $37{ }^{\circ} \mathrm{C}$. Based on our results, the TCA/acetone precipitation method appeared to be more stringent, perhaps due to more extensive washing in the protocol.

\section{Peptide chemical labeling and purification}

Digested peptides from supernatants were desalted, concentrated, and filtered on C18 STop And Go Extraction (STAGE) tips [82]. Reductive dimethylation using formaldehyde isotopologues was performed to differentially label peptides from the different experimental conditions. Light formaldehyde $\left(\mathrm{CH}_{2} \mathrm{O}\right)$ and medium formaldehyde $\left(\mathrm{CD}_{2} \mathrm{O}\right)$ (Cambridge Isotope Laboratories, Andover, MA) were combined with cyanoborohydride $\left(\mathrm{NaBH}_{3} \mathrm{CN}\right.$, Sigma-Aldrich) to give a 4. $\mathrm{Da}$ difference for labeled peptides [83]. Samples from the WT strain were routinely labeled with light formaldehyde, and $P_{G A L 7:: P K A 1 \text { samples were labeled }}$ with medium formaldehyde. Briefly, eluted and dried STAGE-tip peptides were resuspended in $100 \mathrm{mM}$ triethylammonium bicarbonate, and incubated in $200 \mathrm{mM}$ formaldehyde and $20 \mathrm{mM}$ sodium cyanoborohydride for $90 \mathrm{~min}$ in the dark. After labeling, $125 \mathrm{mM} \mathrm{NH}_{4} \mathrm{Cl}$ was added and incubated for $10 \mathrm{~min}$ to react with excess formaldehyde, followed by the addition of acetic acid to a $\mathrm{pH}<2.5$ to degrade sodium cyanoborohydride. For each comparison, equal amounts of labeled peptides were mixed and desalted on C18 STAGE tips.
Protein identification by liquid chromatography-tandem mass spectrometry (LC-MS/MS) and mass spectrometry data analysis

Purified peptides were analyzed using a linear-trapping quadrupole - Orbitrap mass spectrometer (LTQOrbitrap Velos; Thermo Fisher Scientific) on-line coupled to an Agilent 1290 Series HPLC using a nanospray ionization source (Thermo Fisher Scientific). This includes a 2-cm-long, 100- $\mu \mathrm{m}$-inner diameter fused silica trap column, $50-\mu \mathrm{m}$-inner diameter fused silica fritted analytical column and a $20-\mu \mathrm{m}$-inner diameter fused silica gold coated spray tip $(6-\mu \mathrm{m}$-diameter opening, pulled on a P-2000 laser puller from Sutter Instruments, coated on Leica EM SCD005 Super Cool Sputtering Device). The trap column was packed with $5 \mu$ m-diameter Aqua C-18 beads (Phenomenex, www.phenomenex.com) while the analytical column was packed with $3.0 \mu \mathrm{m}$ diameter Reprosil-Pur C-18-AQ beads (Dr. Maisch, www.Dr-Maisch.com). Buffer A consisted of $0.5 \%$ aqueous acetic acid, and buffer B consisted of $0.5 \%$ acetic acid and $80 \%$ acetonitrile in water. Samples were resuspended in buffer A and loaded with the same buffer. Standard 90 min gradients were run from $10 \%$ B to $32 \%$ B over $51 \mathrm{~min}$, then from $32 \% \mathrm{~B}$ to $40 \% \mathrm{~B}$ in the next $5 \mathrm{~min}$, then increased to $100 \% \mathrm{~B}$ over a 2 min period, held at $100 \% \mathrm{~B}$ for $2.5 \mathrm{~min}$, and then dropped to $0 \% \mathrm{~B}$ for another $20 \mathrm{~min}$ to recondition the column. The HPLC system included Agilent 1290 series Pump and Autosampler with Thermostat; temperature was set at $6{ }^{\circ} \mathrm{C}$. The sample was loaded on the trap column at $5 \mu \mathrm{l} / \mathrm{min}$ and the analysis was performed at $0.1 \mu \mathrm{l} / \mathrm{min}$. The LTQ-Orbitrap was set to acquire a full-range scan at 60,000 resolution from 350 to $1600 \mathrm{Th}$ in the Orbitrap to simultaneously fragment the top ten peptide ions by CID and top 5 by HCD (resolution 7500) in each cycle in the LTQ (minimum intensity 1000 counts). Parent ions were then excluded from MS/MS for the next $30 \mathrm{~s}$. Singly charged ions were excluded since in ESI mode peptides usually carry multiple charges. The Orbitrap was continuously recalibrated using lock-mass function [84]. Mass accuracy included an error of mass measurement within $5 \mathrm{ppm}$ and did not exceed $10 \mathrm{ppm}$.

For analysis of mass spectrometry data, centroid fragment peak lists were processed with Proteome Discoverer v. 1.2 (Thermo Fisher Scientific). The search was performed with the Mascot algorithm (v. 2.4) against a database comprised of 6,692 predicted protein sequences from the source organism C. neoformans H99 database (C. neoformans var. grubii H99 Sequencing Project, Broad Institute of Harvard and MIT, http://www.broadinstitute.org/) using the following parameters: peptide mass accuracy 10 parts per million; fragment mass accuracy $0.6 \mathrm{Da}$; trypsin enzyme specificity with 1 max missed cleavages; fixed modifications - carbamidomethyl, variable modifications - 
methionine oxidation, deamidated N, Q and N-acetyl peptides, dimethyl (K), dimethyl (N-term), dimethyl $2 \mathrm{H}(4)$ $(\mathrm{K})$, and dimethyl $2 \mathrm{H}(4)$ (N-term), ESI-TRAP fragment characteristics. Only those peptides with Ion Scores exceeding the individually calculated $99 \%$ confidence limit (as opposed to the average limit for the whole experiment) were considered as accurately identified. The acceptance criteria for protein identification were as follows: only proteins containing at least one unique peptide with a Mascot score $>25$ were considered in the dataset. Quantitative ratios were extracted from the raw data using Proteome Discoverer. Proteome Discoverer parameters - Event Detector: mass precision $4 \mathrm{ppm}$ (corresponds to extracted ion chromatograms at $\pm 12 \mathrm{ppm}$ max error), S/N threshold 1; Precursor Ion Quantifier method set for ' 2 labels' for the formaldehyde labeled samples; Quantitation Method Ratio Calculation - Replace Missing Quantitation Values with Minimum Intensity - yes, Use Single Peak Quantitation Channels - yes, - Protein Quantification - Use All Peptides - yes.

Experimentally determined fold changes for WT and $P_{G A L}:: P K A 1$ strains grown under Pka1-repressed (glucose-containing medium) and Pka1-induced (galactosecontaining medium) conditions were converted to a $\log _{2}$ scale and the average fold change and standard deviation were used for analysis. A fold change of $>10$ was used as a cut-off limit for the time-point and end-point analyses. For the comparative analysis of the time-point samples, the statistical significance of the fold changes of the identified secreted proteins present under both Pka1repressed and Pka1-induced conditions and at equivalent time points (i.e. 16, 48, 72, and $120 \mathrm{hpi}$ ) was assessed for an influence of PKA regulation using a Student's t-test ( $p$-value $<0.05)$. For the comparative analysis of the endpoint samples, the statistical significance of the fold changes of the identified secreted proteins present under both Pka1-repressed and Pka1-induced conditions was evaluated using a Student's $t$-test $(p$-value $<0.05)$. To confirm the statistically significant Pka1-regulated proteins identified from the end-point analysis, a multiplehypothesis testing correction was performed on the secretome data using the Benjamini and Hochberg method with a false discovery rate of 0.05 .

\section{Gene ontology analyses}

Proteins were characterized with Gene Ontology (GO) terms using a local installation of Blast2GO [85]. Gene annotation data of the $C$. neoformans $\mathrm{H} 99$ reference genome were retrieved from the Broad Institute (May 2014) and a copy of the non-redundant (nr) protein database was downloaded from NCBI (May 2014) [86]. The most current associations between the $\mathrm{nr}$ protein database and GO terms were retrieved in May 2014 from Blast2GO. GO terms were assigned to WT proteins and filtered using default settings of the Blast2GO pipeline [85]. We performed GO term enrichment analyses for sets of proteins using hypergeometric tests and the Benjamini and Hochberg false discovery rate multiple testing correction $(p$-value $<0.05)$ implemented in the $\mathrm{R}$ packages GSEABase and GOstats. GO term categories containing singleton entries were excluded. GO categories and enrichment datasets were visualized using the $R$ package ggplot2 [87]. For time-point analyses, GO term classification was performed on unique proteins identified under either Pka1-repressed or Pka1-induced conditions to highlight the overall influence of Pka1 regulation on the secretome profile.

\section{Prediction of the extracellular location of identified proteins}

SignalP 4.1 (http://www.cbs.dtu.dk/services/SignalP/) was used to predict whether identified proteins were secreted based on the presence of a signal peptide. Identified protein sequences were also analyzed using Signal3 L (http://www.csbio.sjtu.edu.cn/bioinf/Signal-3L/) and Phobius (http://phobius.sbc.su.se) to confirm results. Additionally, secreted proteins were analyzed for the presence of a glycophosphatidylinositol (GPI) anchor using GPI-SOM (http://gpi.unibe.ch).

\section{RNA isolation and quantitative Real-Time PCR (qRT-PCR) analysis}

Cells from WT and $P_{G A L 7}:: P K A 1$ strains were prepared for the examination of gene expression by overnight growth in YNB medium followed by dilution to $5.0 \mathrm{x}$ $10^{7}$ cells $/ \mathrm{ml}$ in $5 \mathrm{ml}$ of $\mathrm{MM}+\mathrm{D}$ or $\mathrm{MM}+\mathrm{G}$ and incubation at $30{ }^{\circ} \mathrm{C}$ with agitation for 16 and $96 \mathrm{~h}$. Samples were collected in triplicate for analysis. Cells were collected at the designated time points, flash frozen in liquid $\mathrm{N}_{2}$, and stored at $-80{ }^{\circ} \mathrm{C}$. Total RNA was extracted using an EZ-10 DNAaway RNA Miniprep kit (Bio Basic) according to the manufacturer's protocol. Complementary DNA was synthesized using a Verso cDNA kit (Thermo Scientific) and used for quantitative real-time PCR (qRT-PCR). Primers were designed using Primer3 v.4.0 (http://bioinfo.ut.ee/primer3-0.4.0/) and targeted to the 3' regions of transcripts. qRT-PCR primer sequences (see Additional file 9: Table S6). Relative gene expression was quantified using the Applied Biosystems 7500 Fast Real-time PCR system. Control genes CNAG_00483 (Actin) and CNAG_06699 (GAPDH) were used for normalization, and tested for statistical significance using the Student's t-test. As a control, PKA1 RNA expression levels under Pka1-repressed and Pka1-induced conditions in the WT and $P_{G A L 7:: P K A 1 \text { strains were also }}$ analyzed at various time points to confirm the regulated PKA expression (see Additional file 10: Figure S4). 


\section{RNA blot analysis}

To confirm qRT-PCR results, total RNA was isolated for the $P_{G A L 7}:: P K A 1$ strain grown in $50 \mathrm{ml}$ of $\mathrm{MM}+\mathrm{D}$ or $\mathrm{MM}+\mathrm{G}$ for $16 \mathrm{~h}$. Briefly, cell pellets were collected and flash frozen in liquid $\mathrm{N}_{2}$, followed by overnight lyophilization. One milliliter of buffer 1 (2\% SDS, $68 \mathrm{mM} \mathrm{Na}_{3} \mathrm{C}_{6} \mathrm{H}_{5} \mathrm{O}_{7}, 132 \mathrm{mM} \mathrm{C} \mathrm{H}_{8} \mathrm{O}_{7}, 10 \mathrm{mM}$ EDTA) was added to the samples, along with $600 \mu \mathrm{l}$ of glass beads; samples were subjected to bead beating for two, 3 min intervals at power 3 (BioSpec, Mini-Beadbeater) and subsequently stored on ice. Next, $340 \mu \mathrm{l}$ of buffer 2 (4 M NaCl, $17 \mathrm{mM} \mathrm{Na}_{3} \mathrm{C}_{6} \mathrm{H}_{5} \mathrm{O}_{7}, 33 \mathrm{mM} \mathrm{C}_{6} \mathrm{H}_{8} \mathrm{O}_{7}$ ) was added and samples were inverted several times and incubated on ice for $5 \mathrm{~min}$. Samples were then centrifuged at $15,000 \mathrm{rpm}$ for $10 \mathrm{~min}$, the supernatant fraction was collected and transferred to a new tube, one volume of isopropanol was added, and samples were mixed and incubated at room temperature for $15 \mathrm{~min}$. The pellet was collected following centrifugation at $15,000 \mathrm{rpm}$ for 5 min, and washing of the pellet with $70 \%$ DEPC (Diethylpyrocarbonate)-EtOH was performed. The pellet was collected, air dried, and dissolved in $20 \mu \mathrm{l}$ of DEPC$\mathrm{H}_{2} \mathrm{O}$. The hybridization probes were prepared with a PCR-amplified DNA fragment of CNAG_00483 (Actin) or CNAG_00396 (PKA1) using specific primers (see Additional file 9: Table S6) and labeled with ${ }^{32} \mathrm{P}$ using an Oligolabeling kit (Amersham Biosciences). Scanned images were analyzed using a Bio-Rad ChemiDoc MP Imaging System (see Additional file 11: Figure S5).

\section{Multiple Reaction Monitoring (MRM) sample collection from macrophages, mouse bronchoalveolar lavage, and mouse blood}

The survival rates of the WT, pka1s mutant, and $P_{G A L 7:: P K A 1}$ strains during incubation with macrophages were determined and lysates were prepared for protein analysis [88]. Briefly, cells of the J774A.1 macrophage-like cell line were grown to $80 \%$ confluence in Dulbecco's Modified Eagle's Medium (DMEM; Sigma) supplemented with $10 \%$ fetal bovine serum and $2 \mathrm{mM}$ L-glutamine at $37{ }^{\circ} \mathrm{C}$ and $5 \% \mathrm{CO}_{2}$. The macrophages were stimulated $1 \mathrm{~h}$ prior to infection with $150 \mathrm{ng} / \mathrm{ml}$ phorbol myristate acetate (PMA). Fungal cells were grown in $\mathrm{YNB}$ overnight at $30{ }^{\circ} \mathrm{C}$, followed by inoculation in $\mathrm{MM}+\mathrm{D}$ or $\mathrm{MM}+\mathrm{G}$ at $5.0 \times 10^{7}$ cells $/ \mathrm{ml}$. Following overnight growth, the fungal cells were washed with phosphate-buffered saline (PBS, Invitrogen) and opsonized with $0.5 \mu \mathrm{g} / \mathrm{ml}$ of the anti-capsule monoclonal antibody $18 \mathrm{~B} 7$ in DMEM or DMEM supplemented with $0.20 \%$ glucose or galactose $\left(30 \mathrm{~min}\right.$ at $37^{\circ}$ C). Stimulated macrophages were infected with $2.0 \times 10^{5}$ opsonized fungal cells at a multiplicity of infection (MOI) of $1: 1$ for $2 \mathrm{~h}$ and $24 \mathrm{~h}$ at $37{ }^{\circ} \mathrm{C}$ and $5 \% \mathrm{CO}_{2}$. To measure fungal survival, macrophages containing internalized cryptococcal cells were washed thoroughly four times with PBS and then lysed in $1 \mathrm{ml}$ of sterile $\mathrm{dH}_{2} \mathrm{O}$ for $30 \mathrm{~min}$ at room temperature. Lysate dilutions were plated on YPD agar and incubated at $30{ }^{\circ} \mathrm{C}$ for $48 \mathrm{~h}$, at which time the resulting colony forming units (CFUs) were counted and intracellular rates of infection (\%) were calculated as the ratio of the CFUs at $2 \mathrm{~h}$ and $24 \mathrm{~h}$ over the initial number of macrophages. The statistical significance of differences between WT, pka1 $1 \Delta$ mutant, and $P_{G A L 7:: P K A 1}$ strains were determined by unpaired $t$-tests. For proteomic analysis, lysates from infected macrophage at $24 \mathrm{~h}$ of incubation were collected, flash frozen in liquid $\mathrm{N}_{2}$ and stored at $-80{ }^{\circ} \mathrm{C}$.

Female BALB/c mice (10-12 weeks old) obtained from Charles River Laboratories (Senneville, Ontario, Canada) were used to collect bronchoalveolar lavage (BAL) and blood samples following cryptococcal infection. Three different cultures of $C$. neoformans WT cells were grown overnight in YPD at $30{ }^{\circ} \mathrm{C}$ with agitation, washed in PBS and re-suspended at $1.0 \times 10^{8}$ cells $/ \mathrm{ml}$ in PBS. For collection of BAL, intranasal inoculation of three mice with $100 \mu \mathrm{l}$ of the different WT cell suspensions $\left(1.0 \times 10^{7}\right.$ cells) was performed. For collection of blood samples, intravenous inoculation of three mice with $100 \mu \mathrm{l}$ of the WT cell suspensions $\left(1.0 \times 10^{7}\right.$ cells $)$ was performed. Three mice were selected for the analysis based on established methods for studying fungal burden in mouse models of cryptococcosis [34-37]. At $48 \mathrm{hpi}$, the infected mice were euthanized by $\mathrm{CO}_{2}$ inhalation and $1 \mathrm{ml}$ of BAL fluid and $500 \mu \mathrm{l}$ of blood samples were collected from each mouse [89]. Mouse lavage and blood samples were flash frozen with liquid $\mathrm{N}_{2}$ and stored at $-80{ }^{\circ} \mathrm{C}$. Mouse assays were conducted in accordance with University of British Columbia's Committee on Animal Care (protocol A13-0093).

\section{MRM sample preparation}

Macrophage lysate samples were prepared as described above, followed by trypsin in-solution digestion. Samples were collected for WT and $P_{G A L}:: P K A 1$ strains at $24 \mathrm{hpi}$ in triplicate. Mouse BAL samples were prepared as described above, followed by trypsin in-solution digestion. Samples were collected at 48 hpi following WT inoculation of each of the three mice. For mouse blood samples, highly abundant proteins were removed as previously described [90]. Briefly, proteins were precipitated by the addition of two volumes of acetonitrile and $1.0 \%$ acetic acid, followed by centrifugation at 10,000 rpm for $5 \mathrm{~min}$ at $4{ }^{\circ} \mathrm{C}$. The supernatant was collected and evaporated and the residual proteins were then subjected to trypsin in-solution digestion as described above. Samples were collected at 48 hpi following WT inoculation of each of the three mice. Following trypsin digestion, all samples 
were desalted, concentrated, and filtered on highcapacity C18 STAGE tips.

\section{Peptide selection, internal standardization, and MRM method development}

Skyline (v2.1) was used to build and optimize the MRM method for the relative quantification of peptides [91]. Synthesized peptides for MRM analysis were designed in-house using the following parameters: tryptic peptides, 0 max missed cleavages, minimum of seven and maximum of 25 amino acids, excluding peptides containing Met or Cys residues (if possible) and N-terminal glutamine, hydrophobicity between 10-40 (Sequence Specific Retention Calculator, http://hs2.proteome.ca/SSRCalc/ SSRCalcX.html), desirable spectral intensities (GenePattern ESPPredictor, http://www.broadinstitute.org/ cancer/software/genepattern/modules), and transition settings selecting for precursor charges of 2 and 3, ion charge of 1 , monitoring both $\mathrm{b}$ and $\mathrm{y}$ ions. SpikeTides labeled with stable isotopes (C-term Arg U${ }^{13} \mathrm{C}_{6}$; $\mathrm{U}_{-}-{ }^{15} \mathrm{~N}_{4}$ or Lys $\mathrm{U}_{-}{ }^{13} \mathrm{C}_{6} ; \mathrm{U}_{-}{ }^{15} \mathrm{~N}_{2}$ ) were purchased from JPT Peptide Technologies GmbH (Berlin, Germany). N-terminal Arginine (R) and Lysine (K) were labeled with a stable isotope mass of 10.008269 and 8.014199, respectively. Collision energy (CE) and fragmentor voltage (FV) for each peptide was predicted utilizing Skyline software and then confirmed experimentally [92]. Doubly and triply charged precursor ions were optimized and three to five transitions were measured per peptide. The final MRM method included the monitoring of a total of 23 peptides, representing five proteins (see Additional file 12: Table S7). Stable isotope-labeled peptides were resuspended in $100 \mu \mathrm{l}$ of $0.5 \%$ acetic acid with agitation at room temperature. The peptides were further diluted and combined to result in final concentrations of $100 \mathrm{fmol} / \mu \mathrm{l}$ to $1 \mathrm{pmol} / \mu \mathrm{l}$ of each peptide. Five $\mu \mathrm{l}$ of the peptide mixture was injected into an Agilent 6460 Triple Quadrupole (Agilent) for data acquisition and peptide optimization.

\section{Mass spectrometry and data analysis for MRM}

MRM assays were performed on an Agilent 6460 Triple Quadrupole coupled with Agilent 1200 Series HPLC. The instrument was operated in positive electrospray ionization mode using MassHunter Workstation Data Acquisition (v.B.04.04, Agilent). Chromatography was performed on a Large Capacity Chip with $160 \mathrm{nl}$ Trap, analytical column was $150 \mathrm{~mm}$ x $75 \mu \mathrm{m}$, stationary phase for both trapping and analytical columns were Zorbax-SB C-18, $300 \mathrm{~A}$ and $5 \mu \mathrm{m}$ particles (Agilent). Peptides were separated using gradient elution with a stable flow of $0.30 \mu \mathrm{l} / \mathrm{min}$, beginning with $97 \%$ buffer A (97\% $\mathrm{dH}_{2} \mathrm{O}, 3 \%$ acetonitrile, $0.1 \%$ formic acid (FA)) and $3 \%$ buffer $\mathrm{B}\left(10 \% \mathrm{dH}_{2} \mathrm{O}, 90 \% \mathrm{ACN}, 0.1 \%\right.$ FA) followed by a step gradient of buffer B from 3 to $80 \%$, which was achieved at $10.5 \mathrm{~min}$. Subsequent equilibration was performed for $4.5 \mathrm{~min}$ at $3 \%$ buffer B. The column was maintained at room temperature during analysis, and the samples were kept at $4-7{ }^{\circ} \mathrm{C}$. The MS was operating in selective reaction mode using electrospray ionization in positive ion mode, with a capillary voltage of $1850 \mathrm{~V}$ and a source temperature of $325{ }^{\circ} \mathrm{C}$. Cone voltage was static, collision energies and fragmentor voltages were optimized for each compound individually (see Additional file 13: Table S8). Peak identification was performed using MassHunter Qualitative Analysis (Agilent).

Quantification of natural proteins was performed using peak areas relative to the known amounts of added isotopically-labeled synthetic peptides during a multiplexed MRM run. Natural protein levels were identified in triplicate from the following matrices: WT and $P_{\text {GAL7: }}$ PKA1 macrophage lysate $\mathrm{MM}+\mathrm{D}$ and $\mathrm{MM}+\mathrm{G}$ collected at $24 \mathrm{hpi}$; BAL collected at 48 hpi from three different mice inoculated independently with the WT strain; and blood collected at $48 \mathrm{hpi}$ from three different mice inoculated independently with the WT strain. Each biological sample was assayed independently in triplicate. Experimentally determined peak areas and the subsequent quantification values were converted to a $\log _{2}$ scale, and the average amount of identified peptide $+/-$ S.D. was reported. Positive association of natural peptides to their respective isotopically-labeled peptides was determined based on co-elution patterns. For positive identification of a natural protein in a collected sample, at least one peptide with a minimum of two transitions must be identified or a minimum of two peptides with at least one transition each must be present.

\section{Validation of secretome data}

Enzymatic activity was assayed for $\alpha$-amylase and acid phosphatase. The assays were performed with kits for both enzymes according to the manufacturer's protocol (BioVision Incorporated) (see Additional file 14: Figure S6). To confirm that proteins identified in the secretome were a result of secretion and not a product of cell lysis, a PCR was performed on secretome samples from Pka1-repressed conditions for WT strain at 96 hpi. Actin (CNAG_00483) and PKA1 (CNAG_00396) were used as control genes for amplification (see Additional file 15: Figure S7) [48].

\section{Availability of supporting data}

The mass spectrometry proteomics data have been deposited to the ProteomeXchange Consortium [93] via the PRIDE partner repository [94] with the dataset 
identifier PXD002731 and the PASSEL partner repository with the dataset identifier PASS00736.

\section{Ethics statement}

Mouse assays were conducted in accordance with University of British Columbia's Committee on Animal Care (protocol A13-0093).

\section{Additional files}

Additional file 1: Table S1. Quantitative proteomic analysis of the secretome of C. neoformans at 16, 48, 72, and 120 hpi under Pka1-repressed (glucose-containing medium) conditions. (DOCX 94 kb)

Additional file 2: Table S2. Quantitative proteomic analysis of the secretome of C. neoformans at 16, 48, 72, and 120 hpi under Pka1-induced (galactose-containing medium) conditions. (DOCX 99 kb)

Additional file 3: Table S3. Proteins identified in the secretome of $C$. neoformans from both the $96 \mathrm{hpi}$ (end-point) samples and the time course $(16,48,72,120 \mathrm{hpi})$ samples prepared in Pka1-repressed (glucose-containing medium) and Pka1-induced (galactose-containing medium) conditions. (DOCX $94 \mathrm{~kb}$ )

Additional file 4: Table S4. Quantitative proteomic analysis of the secretome of C. neoformans at 96 hpi under Pka1-repressed (glucosecontaining medium) conditions. (DOCX $92 \mathrm{~kb}$ )

Additional file 5: Table S5. Quantitative proteomic analysis of the secretome of C. neoformans at 96 hpi under Pka1-induced (galactosecontaining medium) conditions. (DOCX $82 \mathrm{~kb}$ )

Additional file 6: Figure S1. Enrichment of genes represented in the secretome for cells grown under Pka1-repressed (D) and Pka1-induced (G) conditions compared to all genes present in the WT strain. Enrichment based on GO terms associated with cellular compartment (CC). (TIFF 275 kb)

Additional file 7: Figure S2. Comparison of GO terms classifications of cellular components from the identified secreted proteins grown under Pka1-repressed and Pka1-induced conditions compared to proteins represented in the Fungal Secretome Knowledgebase. (TIFF 1613 kb)

Additional file 8: Figure S3. Comparison of GO terms classifications of molecular function from the identified secreted proteins grown under Pka1-repressed and Pka1-induced conditions compared to proteins represented in the Fungal Secretome Knowledgebase. (TIFF 1149 kb)

Additional file 9: Table S6. Primers sequences used for amplification of CDNA for qRT-PCR analysis and genomic DNA for cell lysis control PCR. (DOCX $21 \mathrm{~kb}$ )

Additional file 10: Figure S4. RNA expression levels of PKA1 measured by qRT-PCR in $P_{\text {GAL }} \div .: P K A 1$ and WT strains, grown in Pka1-repressed (glucose-containing medium) and Pka1-induced (galactose-containing medium) conditions at 4, 16, 48 and 96 hpi. Samples evaluated in triplicate, values reported as average $\log _{2}$ fold change \pm S.D. Actin and GAPDH were used as controls and PKA1 expression was assessed under the different growth conditions. The results show an up-regulation of PKA1 mRNA under Pka1-inducible conditions. (TIFF $610 \mathrm{~kb}$ )

Additional file 11: Figure S5. RNA expression levels of PKA1 measured by Northern blot as a method for validating the qRT-PCR results. RNA was extracted from $P_{\text {GAL }}$ :PKA1 cells grown under Pka1-repressed (glucosecontaining medium) and Pka1-induced (galactose-containing medium) conditions $16 \mathrm{hpi}$. Actin was used as a control and PKA1 expression was assessed under the different growth conditions. The results show an up-regulation of PKA1 mRNA under Pka1-inducible conditions.

(TIFF $342 \mathrm{~kb}$ )

Additional file 12: Table S7. Proteins selected for Multiple Reaction Monitoring assays and their respective isotopically-labeled synthetic peptides (DOCX $87 \mathrm{~kb}$ )

Additional file 13: Table S8. Isotopically-labeled peptides monitored during MRM multiplex assay. (DOCX 112 kb)
Additional file 14: Figure S6. Enzyme activity for A) Amylase and B) Acid phosphatase in the WT and $P_{\text {GAL }}:$. PKA1 strains of $C$. neoformans under Pka1-repressed (glucose-containing medium) and Pka1-induced (galactose-containing medium) conditions. Values are reported as an average \pm standard deviation for three independent replicates. For statistical analysis, a Student's t-test was performed and a line denotes $p$-value $<0.05$. (TIFF $489 \mathrm{~kb}$ )

Additional file 15: Figure S7. PCR to confirm absence of cellular factors due to cell lysis in secretome of C. neoformans. PCR for the A) Actin and B) PKA1 genes were performed using either $C$. neoformans WT genomic DNA (6 pg to $100 \mathrm{ng}$ ) or WT supernatant samples (250 ng or $1000 \mathrm{ng}$ of total protein). Control lane contains $6 \mathrm{pg}$ of gDNA spiked into $250 \mathrm{ng}$ of supernatant. (TIFF $1093 \mathrm{~kb}$ )

\section{Abbreviations}

AIDS: Acquired immune deficiency syndrome; BAL: Bronchoalveolar lavage; CAMP: cyclic-adenosine monophosphate; CID: Collision induced dissociation CFU: Colony forming units; DEPC: Diethylpyrocarbonate; DMEM: Dulbecco's modified eagle medium; FunSecKB: Fungal Secretome KnowledgeBase; GO: Gene ontology; GPCR: G-protein coupled receptor;

GPI: Glycophosphatidylinositol; HCD: Higher-energy collision dissociation; HIV: Human immunodeficiency virus; hpi: Hours post inoculation; HPLC: High performance liquid chromatography; MM (D/G): Minimal media (glucose/ galactose); MRM: Multiple reaction monitoring; NEM: N-ethylmaleimide; PBS: Phosphate buffered saline; PKA: Protein kinase A; PMA: Phorbol myristate acetate; qRT-PCR: Quantitative real time - polymerase chain reaction; SID: Stable isotope dilutions; STAGE: Stop and go extraction; WT: Wild-type; YPD: Yeast peptone dextrose.

\section{Competing interests}

The authors declare that they have no competing interests.

\section{Authors' contributions}

JMHG, LJF, and JWK conceived of the study and participated in its design. JMHG carried out the quantitative proteomic sample preparation, data analysis, and interpretation, the targeted proteomic sample preparation, data analysis, and interpretation, validation studies, and drafted the manuscript. DC performed the $\mathrm{GO}$ enrichment analyses. MC performed the macrophage assays. NS provided technical assistance for the quantitative proteomic analysis and data processing. JWK assisted in drafting of the manuscript. All authors read and approved the final manuscript.

\section{Authors' information}

Not applicable.

\section{Acknowledgements}

The authors thank J. Choi for strain construction, and M. Kretschmer, J. Gouw, J. Rogalski, and N. Scott for discussions and technical assistance. We also thank D. Oliveira for the collection of mouse samples. This work was supported by an NSERC fellowship to JG, CIHR open operating grants to JWK and LF, and a Burroughs Wellcome Fund Scholar Award in Molecular Pathogenic Mycology (JWK).

\section{Author details}

${ }^{1}$ Michael Smith Laboratories, University of British Columbia, Vancouver, BC V6T 1Z4, Canada. ${ }^{2}$ Department of Microbiology and Immunology, University of British Columbia, Vancouver, BC V6T 1Z4, Canada. ${ }^{3}$ Centre for High-Throughput Biology, University of British Columbia, Vancouver, BC V6T 1Z4, Canada.

Received: 7 May 2015 Accepted: 25 September 2015

Published online: 09 October 2015

\section{References}

1. Mitchell TG, Perfect JR. Cryptococcosis in the era of AIDS-100 years after the discovery of Cryptococcus neoformans. Clin Microbiol Rev. 1995;8(4):515-48.

2. Park BJ, Wannemuehler KA, Marston BJ, Govender N, Pappas PG, Chiller TM. Estimation of the current global burden of cryptococcal meningitis among persons living with HIV/AIDS. AIDS. 2009;23(4):525-30. 
3. Bulmer GS, Sans MD, Gunn CM. Cryptococcus neoformans. I. Nonencapsulated mutants. J Bacteriol. 1967;94(5):1475-9.

4. Kwon-Chung KJ, Polacheck I, Popkin TJ. Melanin-lacking mutants of Cryptococcus neoformans and their virulence for mice. J Bacteriol. 1982;150(3):1414-21.

5. Rhodes JC, Polacheck I, Kwon-Chung KJ. Phenoloxidase activity and virulence in isogenic strains of Cryptococcus neoformans. Infect Immun. 1982;36(3):1175-84.

6. Kwon-Chung KJ, Rhodes JC. Encapsulation and melanin formation as indicators of virulence in Cryptococcus neoformans. Infect Immun. 1986;51(1):218-23.

7. Polacheck I, Kwon-Chung KJ. Melanogenesis in Cryptococcus neoformans. J Gen Microbiol. 1988;134(4):1037-41.

8. Chang YC, Kwon-Chung KJ. Complementation of a capsule-deficient mutation of Cryptococcus neoformans restores its virulence. Mol Cell Biol. 1994;14(7):4912-9.

9. Casadevall A, Perfect JR. Cryptococcus neoformans: Washington. D.C.: ASM Press; 1998

10. Ghannoum MA. Potential role of phospholipases in virulence and fungal pathogenesis. Clin Microbiol Rev. 2000;13(1):122-43.

11. Cox G, McDade H, Chen S, Tucker S, Gottfredsson M, Wright L, et al. Extracellular phospholipase activity is a virulence factor for Cryptococcus neoformans. Mol Microbiol. 2001;39(1):166-75.

12. Maruvada R, Zhu L, Pearce D, Zheng Y, Perfect J, Kwon-Chung KJ, et al. Cryptococcus neoformans phospholipase B1 activates host cell Rac1 for traversal across the blood-brain barrier. Cell Microbiol. 2012;14(10):1544-53.

13. Chen L, Blank E, Casadevall A. Extracellular proteinase activity of Cryptococcus neoformans. Clin Diagn Lab Immunol. 1996;3(5):570-4.

14. Vu K, Tham R, Uhrig JP, Thompson III R, Pombejra SN, Jamklang M, et al. Invasion of the central nervous system by Cryptococcus neoformans requires a secreted fungal metalloprotease. Mbio. 2014;5(3):e01101-14.

15. Rodrigues M, dos Reis F, Puccia R, Travassos L, Alviano C. Cleavage of human fibronectin and other basement membrane-associated proteins by a Cryptococcus neoformans serine proteinase. Microb Pathog. 2003;34(2):65-71.

16. Alspaugh JA, Perfect JR, Heitman J. Cryptococcus neoformans mating and virulence are regulated by the G-protein alpha subunit GPA1 and CAMP. Genes Dev. 1997:11(23):3206-17.

17. D'Souza CA, Alspaugh JA, Yue C, Harashima T, Cox GM, Perfect JR, et al. Cyclic AMP-dependent protein kinase controls virulence of the fungal pathogen Cryptococcus neoformans. Mol Cell Biol. 2001;21(9):3179-91.

18. Kozubowski L, Lee SC, Heitman J. Signalling pathways in the pathogenesis of Cryptococcus. Cell Microbiol. 2009;11(3):370-80.

19. Kronstad JW, Attarian R, Cadieux B, Choi J, D'Souza CA, Griffiths EJ, et al. Expanding fungal pathogenesis: Cryptococcus breaks out of the opportunistic box. Nat Rev Microbiol. 2011;9(3):193-203.

20. McDonough KA, Rodriguez A. The myriad roles of cyclic AMP in microbial pathogens: from signal to sword. Nat Rev Microbiol. 2012;10(1):27-38.

21. Hicks JK, D'Souza CA, Cox GM, Heitman J. Cyclic AMP-dependent protein kinase catalytic subunits have divergent roles in virulence factor production in two varieties of the fungal pathogen Cryptococcus neoformans. Eukaryot Cell. 2004;3(1):14-26.

22. Hu G, Steen BR, Lian T, Sham AP, Tam N, Tangen KL, et al. Transcriptional regulation by protein kinase $A$ in Cryptococcus neoformans. PLoS Pathog. 2007;3(3):e42.

23. Rodrigues ML, Nimrichter L, Oliveira DL, Frases S, Miranda K, Zaragoza O, et al. Vesicular polysaccharide export in Cryptococcus neoformans is a eukaryotic solution to the problem of fungal trans-cell wall transport. Eukaryotic Cell. 2007;6(1):48-59.

24. Rodrigues ML, Nakayasu ES, Oliveira DL, Nimrichter L, Nosanchuk JD, Almeida IC, et al. Extracellular vesicles produced by Cryptococcus neoformans contain protein components associated with virulence. Eukaryotic Cell. 2008;7(1):58-67.

25. Panepinto J, Komperda K, Frases S, Park Y, Djordjevic JT, Casadevall A, et al. Sec6-dependent sorting of fungal extracellular exosomes and laccase of Cryptococcus neoformans. Mol Microbiol. 2009;71(5):1165-76.

26. Chayakulkeeree M, Johnston SA, Oei JB, Lev S, Williamson PR, Wilson CF, et al. SEC14 is a specific requirement for secretion of phospholipase B1 and pathogenicity of Cryptococcus neoformans. Mol Microbiol. 2011;80(4):1088-101.

27. Lev S, Desmarini D, Li C, Chayakulkeeree M, Traven A, Sorrell TC, et al. Phospholipase C of Cryptococcus neoformans regulates homeostasis and virulence by providing inositol trisphosphate as a substrate for Arg1 kinase. Infect Immun. 2013;81(4):1245-55.
28. Lev S, Crossett B, Cha SY, Desmarini D, Li C, Chayakulkeeree M, et al. Identification of Aph1, a phosphate-regulated, secreted, and vacuolar acid phosphatase in Cryptococcus neoformans. Mbio. 2014;5(5):e01649-14.

29. Choi J, Vogl AW, Kronstad JW. Regulated expression of cyclic AMPdependent protein kinase A reveals an influence on cell size and the secretion of virulence factors in Cryptococcus neoformans. Mol Microbiol. 2012;85(4):700-15.

30. Zellner M, Winkler W, Hayden H, Diestinger M, Eliasen M, Gesslbauer B, et al. Quantitative validation of different protein precipitation methods in proteome analysis of blood platelets. Electrophoresis. 2005;26(12):2481-9.

31. Loftus B, Fung E, Roncaglia P, Rowley D, Amedeo P, Bruno D, et al. The genome of the basidiomycetous yeast and human pathogen Cryptococcus neoformans. Science. 2005;307(5713):1321-4.

32. Lum G, Min XJ. FunSecKB: the Fungal Secretome KnowledgeBase. Database - the Journal of Biological Databases and Curation. 2011;2011: doi:10.1093/ database/bar001.

33. Abbatiello SE, Mani DR, Keshishian H, Carr SA. Automated Detection of Inaccurate and Imprecise Transitions in Peptide Quantification by Multiple Reaction Monitoring Mass Spectrometry. Clin Chem. 2010;56(2):291-305.

34. Kretschmer M, Wang J, Kronstad JW. Peroxisomal and Mitochondrial beta-Oxidation Pathways Influence the Virulence of the Pathogenic Fungus Cryptococcus neoformans. Eukaryotic Cell. 2012;11(8):1042-54.

35. Crabtree J, Okagaki L, Wiesner D, Strain A, Nielsen J, Nielsen K. Titan cell production enhances the virulence of Cryptococcus neoformans. Infect Immun. 2012;80(11):3776-85.

36. Sun T, Ju X, Gao H, Wang T, Thiele DJ, Li J, et al. Reciprocal functions of Cryptococcus neoformans copper homeostasis machinery during pulmonary infection and meningoencephalitis. Nat Commun. 2014;5:5550.

37. Hu G, Caza M, Cadieux B, Chan V, Liu V, Kronstad J. Cryptococcus neoformans Requires the ESCRT Protein Vps23 for Iron Acquisition from Heme, for Capsule Formation, and for Virulence. Infect Immun. 2013;81(1):292-302.

38. Yoneda A, Doering TL. A eukaryotic capsular polysaccharide is synthesized intracellularly and secreted via exocytosis. Mol Biol Cell. 2006;17(12):5131-40.

39. Wolf JM, Espadas-Moreno J, Luque-Garcia J, Casadevall A. Interaction of Cryptococcus neoformans extracellular vesicles with the cell wall. Eukaryotic Cell. 2014;13(12):1484.

40. Klein C, Struhl K. Protein Kinase A mediates growth-regulated expression of yeast ribosomal-protein genes by modulating Rap1 transcriptional activity. Mol Cell Biol. 1994;14(3):1920-8.

41. Price MS, Betancourt-Quiroz M, Price JL, Toffaletti DL, Vora H, Hu G, et al. Cryptococcus neoformans requires a functional glycolytic pathway for disease but not persistence in the host. Mbio. 2011:2(3):e00103.

42. Silveira CP, Piffer AC, Kmetzsch L, Fonseca FL, Soares DA, Staats CC, et al. The heat shock protein ( $\mathrm{Hsp}$ ) 70 of Cryptococcus neoformans is associated with the fungal cell surface and influences the interaction between yeast and host cells. Fungal Genet Biol. 2013;60:53-63.

43. Lian T, Simmer M, D'Souza C, Steen B, Zuyderduyn S, Jones S, et al. Ironregulated transcription and capsule formation in the fungal pathogen Cryptococcus neoformans. Mol Microbiol. 2005;55(5):1452-72.

44. Cadieux B, Lian T, Hu G, Wang J, Biondo C, Teti G, et al. The Mannoprotein Cig1 supports iron acquisition from heme and virulence in the pathogenic fungus Cryptococcus neoformans. J Infect Dis. 2013;207(8):1339-47.

45. O'Meara TR, Norton D, Price MS, Hay C, Clements MF, Nichols CB, et al. Interaction of Cryptococcus neoformans Rim101 and protein kinase A regulates capsule. PLos Pathogens. 2010;6(2):e1000776.

46. O'Meara TR, Holmer SM, Selvig K, Dietrich F, Alspaugh JA. Cryptococcus neoformans Rim101 Is associated with cell wall remodeling and evasion of the host immune responses. Mbio. 2013;4(1):e00522-12.

47. O'Meara TR, Xu W, Selvig KM, O'Meara MJ, Mitchell AP, Alspaugh JA. The Cryptococcus neoformans Rim101 transcription factor directly regulates genes required for adaptation to the host. Mol Cell Biol. 2014;34(4):673-84.

48. Holbrook ED, Edwards JA, Youseff BH, Rappleye CA. Definition of the extracellular proteome of pathogenic phase Histoplasma capsulatum. J Proteome Res. 2011;10(4):1929-43.

49. Biondo C, Mancuso G, Midiri A, Bombaci M, Messina L, Beninati C, et al. Identification of major proteins secreted by Cryptococcus neoformans. Fems Yeast Res. 2006;6(4):645-51.

50. Macekova D, Farkas V, Kishida E, Takeo K. Ecto-glycanases and metabolic stability of the capsule in Cryptococcus neoformans. J Basic Microbiol. 2006;46(6):470-9. 
51. Eigenheer RA, Lee YJ, Blumwald E, Phinney BS, Gelli A. Extracellular glycosylphosphatidylinositol-anchored mannoproteins and proteases of Cryptococcus neoformans. Fems Yeast Res. 2007;7(4):499-510.

52. Meyer M, Phaff H. Survey for alpha-(1-]3)-glucanase activity among yeasts. J Bacteriol. 1977;131(2):702-6.

53. Sarthy A, McGonigal T, Coen M, Frost D, Meulbroek J, Goldman R. Phenotype in Candida albicans of a disruption of the BGL2 gene encoding a 1,3-beta-glucosyltransferase. Microbiology-Uk. 1997;143:367-76.

54. Liu L, Tewari R, Williamson P. Laccase protects Cryptococcus neoformans from antifungal activity of alveolar macrophages. Infect Immun. 1999;67(11):6034-9.

55. Casadevall A, Rosas A, Nosanchuk J. Melanin and virulence in Cryptococcus neoformans. Curr Opin Microbiol. 2000;3(4):354-8.

56. Baker LG, Specht CA, Donlin MJ, Lodge JK. Chitosan, the deacetylated form of chitin, is necessary for cell wall integrity in Cryptococcus neoformans. Eukaryotic Cell. 2007;6(5):855-67.

57. Gilbert NM, Baker LG, Specht CA, Lodge JK. A glycosylphosphatidylinositol anchor is required for membrane localization but dispensable for cell wall association of chitin deacetylase 2 in Cryptococcus neoformans. Mbio. 2012;3(1):e00007

58. Liu OW, Chun CD, Chow ED, Chen C, Madhani HD, Noble SM. Systematic genetic analysis of virulence in the human fungal pathogen Cryptococcus neoformans. Cell. 2008;135(1):174-88.

59. Chun CD, Brown JCS, Madhani HD. A major role for capsule-independent phagocytosis-inhibitory mechanisms in mammalian infection by Cryptococcus neoformans. Cell Host Microbe. 2011;9(3):243-51.

60. lefuji $H$, Chino M, Kato M, limura Y. Raw-starch-digesting and thermostable alpha-amylase from the yeast Cryptococcus sp. S-2: Purification, characterization, cloning and sequencing. Biochem J. 1996;318:989-96.

61. Leuthner B, Aichinger C, Oehmen E, Koopmann E, Muller O, Muller P, et al. $\mathrm{A} \mathrm{H}_{2} \mathrm{O}_{2}$-producing glyoxal oxidase is required for filamentous growth and pathogenicity in Ustilago maydis. Mol Gen Genomics. 2005;272(6):639-50.

62. Ngamskulrungroj P, Price J, Sorrell T, Perfect JR, Meyer W. Cryptococcus gattii virulence composite: candidate genes revealed by microarray analysis of high and less virulent Vancouver Island outbreak strains. PLos One. 2011;6(1):e16076.

63. Greenbaum D, Jansen R, Gerstein M. Analysis of mRNA expression and protein abundance data: an approach for the comparison of the enrichment of features in the cellular population of proteins and transcripts. Bioinformatics. 2002;18(4):585-96.

64. Chen G, Edwards T, D'souza VM, Holz RC. Mechanistic studies on the aminopeptidase from Aeromonas proteolytica: a two-metal ion mechanism for peptide hydrolysis. Biochemistry. 1997;36(14):4278-86.

65. Dickman M, Yarden O. Serine/threonine protein kinases and phosphatases in filamentious fungi. Fungal Genet Biol. 1999;26(2):99-117.

66. Zhan X, Hong Y, Zhu T, Mitchell A, Deschenes R, Guan K. Essential functions of protein tyrosine phosphatases PTP2 and PTP3 and RIM11 tyrosine phosphorylation in Saccharomyces cerevisiae meiosis and sporulation. Mol Biol Cell. 2000;11(2):663-76.

67. Collopy-Junior I, Esteves FF, Nimrichter L, Rodrigues ML, Alviano CS, MeyerFernandes JR. An ectophosphatase activity in Cryptococcus neoformans. Fems Yeast Res. 2006;6(7):1010-7.

68. Kretschmer M, Reiner E, Hu G, Tam N, Oliveira DL, Caza M, et al. Defects in phosphate acquisition and storage influence virulence of Cryptococcus neoformans. Infect Immun. 2014;82(7):2697-712.

69. Casadevall A, Nosanchuk JD, Williamson P, Rodrigues ML. Vesicular transport across the fungal cell wall. Trends Microbiol. 2009;17(4):158-62.

70. Doering TL. How sweet it is! Cell wall biogenesis and polysaccharide capsule formation in Cryptococcus neoformans. Annu Rev Microbiol. 2009;63:223-47.

71. Eisenman HC, Frases S, Nicola AM, Rodrigues ML, Casadevall A. Vesicleassociated melanization in Cryptococcus neoformans. Microbiology-Sgm. 2009;155:3860-7.

72. Oliveira DL, Nakayasu ES, Joffe LS, Guimaraes AJ, Sobreira TJP, Nosanchuk $J D$, et al. Characterization of yeast extracellular vesicles: evidence for the participation of different pathways of cellular traffic in vesicle biogenesis. PLos One. 2010;5(6):e11113.

73. Tucci P, González-Sapienza G, Marin M. Pathogen-derived biomarkers for active tuberculosis diagnosis. Front Microbiol. 2014;5.

74. Schuetz AN. Invasive fungal infections biomarkers and molecular approaches to diagnosis. Clin Lab Med. 2013;33(3):505-25.
75. Affolter K, Tamm M, Jahn K, Halter J, Passweg J, Hirsch HH, et al. Galactomannan in bronchoalveolar lavage for diagnosing invasive fungal disease. Am J Respir Crit Care Med. 2014;190(3):309-17.

76. Kirkham P. Oxidative stress and macrophage function: a failure to resolve the inflammatory response. Biochem Soc Trans. 2007;35:284-7.

77. Perrotta I, Carito V, Russo E, Tripepi S, Aquila S, Donato G. Macrophage autophagy and oxidative stress: an ultrastructural and immunoelectron microscopical study. Oxidative Med Cell Longev. 2011;2011:282739.

78. Marion CL, Rappleye CA, Engle JT, Goldman WE. An alpha-(1,4)-amylase is essential for alpha-(1,3)-glucan production and virulence in Histoplasma capsulatum. Mol Microbiol. 2006;62(4):970-83.

79. Damerval C, de Vienne D, Zivy M, Thiellement H. Technical improvements in two-dimensional electrophoresis increase the level of genetic variation detected in wheat seedling proteins. Electrophoresis. 1986;7:52-4.

80. Foster L, De Hoog CL, Mann M. Unbiased quantitative proteomics of lipid rafts reveals high specificity for signaling factors. Proc Natl Acad Sci U S A. 2003;100(10):5813-8.

81. Fang $Y$, Robinson DP, Foster $L$. Quantitative analysis of proteome coverage and recovery rates for upstream fractionation methods in proteomics. J Proteome Res. 2010;9(4):1902-12.

82. Rappsilber J, Ishihama Y, Mann M. Stop and go extraction tips for matrixassisted laser desorption/ionization, nanoelectrospray, and LC/MS sample pretreatment in proteomics. Anal Chem. 2003;75(3):663-70.

83. Boersema PJ, Aye TT, van Veen TA, Heck AJ, Mohammed S. Triplex protein quantification based on stable isotope labeling by peptide dimethylation applied to cell and tissue lysates. Proteomics. 2008;8(22):4624-32.

84. Olsen J, de Godoy L, Li G, Macek B, Mortensen P, Pesch R, et al. Parts per million mass accuracy on an orbitrap mass spectrometer via lock mass injection into a C-trap. Mol Cell Proteomics. 2005;4(12):2010-21.

85. Conesa A, Gotz S, Garcia-Gomez J, Terol J, Talon M, Robles M. Blast2GO: a universal tool for annotation, visualization and analysis in functional genomics research. Bioinformatics. 2005;21 (18):3674-6.

86. Janbon G. Introns in Cryptococcus neoformans. Mycoses. 2014;57:27-27.

87. Wickham H. A layered grammar of graphics. J Comput Graph Stat. 2010;19(1):3-28

88. Griffiths EJ, Hu G, Fries B, Caza M, Wang J, Gsponer J, et al. A defect in ATPcitrate lyase links acetyl-CoA production, virulence factor elaboration and virulence in Cryptococcus neoformans. Mol Microbiol. 2012;86(6):1404-23.

89. Hu G, Cheng P, Sham A, Perfect JR, Kronstad JW. Metabolic adaptation in Cryptococcus neoformans during early murine pulmonary infection. Mol Microbiol. 2008;69(6):1456-75.

90. Polson C, Sarkar P, Incledon B, Raguvaran V, Grant R. Optimization of protein precipitation based upon effectiveness of protein removal and ionization effect in liquid chromatography-tandem mass spectrometry. J Chromatogr B Analyt Technol Biomed Life Sci. 2003;785(2):263-75.

91. MacLean B, Tomazela DM, Shulman N, Chambers M, Finney GL, Frewen B, et al. Skyline: an open source document editor for creating and analyzing targeted proteomics experiments. Bioinformatics. 2010;26(7):966-8.

92. MacLean B, Tomazela DM, Abbatiello SE, Zhang S, Whiteaker JR, Paulovich $A G$, et al. Effect of collision energy optimization on the measurement of peptides by selected reaction monitoring (SRM) mass spectrometry. Anal Chem. 2010;82(24):10116-24.

93. Vizcaíno JA, Deutsch EW, Wang R, Csordas A, Reisinger F, Ríos D, et al. ProteomeXchange provides globally co-ordinated proteomics data submission and dissemination. Nat Biotechnol. 2014;30(3):223-6.

94. Vizcaino JA, Cote RG, Csordas A, Dianes JA, Fabregat A, Foster JM, et al. The Proteomics Identifications (PRIDE) database and associated tools: status in 2013. Nucleic Acids Res. 2013;41(D1):D1063-9. 